\title{
Evolução da distribuição familiar da riqueza imobiliária no Brasil: 1995-2004
}

\author{
Paulo Tafner ${ }^{1}$ \\ Márcia de Carvalho ${ }^{2}$
}

\begin{abstract}
Resumo: A partir dos dados disponíveis nas PNADs para os anos de 1995 e 2004, o trabalho estima o valor do aluguel residencial, utilizando o método de preço hedônico. A partir dos coeficientes estimados dos atributos físicos e da localização dos imóveis, imputa um valor de aluguel para os imóveis não alugados. Admitida a hipótese de constância na relação valor de aluguel/ valor do imóvel, obtém-se o valor do estoque de residências. Usando as informações de aluguéis pagos e recebidos - disponíveis nas PNADs - apropria-se a cada unidade familiar o valor de estoque em residência. Com os resultados obtidos e feita a ressalva das famílias que não tendo imóvel alugam imóveis cujo valor é muito superior ao valor médio dos imóveis alugados, calcula-se o Índice de Gini para os dois anos analisados. O trabalho conclui que entre os dois anos analisados houve expressiva melhora no perfil da distribuição do valor do estoque de residências, tendo o Gini passado de 0,69 para 0,61.
\end{abstract}

Palavras-chave: desigualdade; distribuição de renda e propriedade; padrão de vida; estimação de preços hedônicos.

\section{The distribution of real state income in Brazil: 1995- \\ 2004}

Abstract: From the PNAD's data covering 1995 and 2004 this paper estimates the value of house rents. Using the estimated coefficients of the physical attributes and of the location of the rented houses, we impute an "estimated rent value" for owned houses. In following, admitted constant the relation between rents and value of stock, we estimate the real value of house stock for those years. Based on PNAD's data on received rents. We also distribute to each family the

1 Ipea/Dimac e Ucam/MME. E-mail: ptafner@ipea.gov.br

2 Ucam/MME. E-mail: mmcarv@globo.com 
corresponding value of stock in properties. Excluding the families that do not have any property and are able to pay rent corresponding to properties which price is higher than the average price of rented houses, the Index of Gini is calculated for both years. The paper concludes that there was an expressive improvement in the shape of distribution of wealth ownership in this period, since the Gini coefficient had changed from o,69 to o,61 between 1995 and 2004.

Key words: inequality; distribution of income and ownership; living standards; hedonic price estimation.

\section{JEL: D31}

\section{Introdução}

Estudos o sobre valor de estoque de capital residencial têm mostrado a importância desse ativo em aspectos relevantes da vida econômica e social $^{3}$. Em particular, os estudos sobre a distribuição pessoal ou familiar do estoque de riqueza enfatizam seu papel relevante na determinação da desigualdade de oportunidades sociais e na definição da estrutura de estratificação social $^{4}$.

O presente trabalho tem por objetivo analisar como o estoque de riqueza, sob a forma de imóveis residenciais permanentes, está distribuído entre as famílias brasileiras ${ }^{5}$, para os anos de 1995 e 2004. A partir do modelo apresentado por Reis et al. (2001) e a partir dos dados disponíveis nas PNADs para os dois anos mencionados, estimamos o valor do aluguel residencial e utilizamos os coeficientes estimados dos atributos físicos dos imóveis e de sua localização para imputar um valor de aluguel para os imóveis não alugados. Utilizando uma constante que expressa a relação valor de aluguel/valor do imóvel, obtém-se o valor do estoque de residências na economia que, complementado pelas informações de aluguéis pagos e recebidos das PNADs, permite a apropriação a cada unidade familiar do valor de estoque em residência.

Esse valor representa uma aproximação bastante razoável do estoque de riqueza imobiliária que cada família possui ${ }^{6}$. Feita a ressalva daquelas unidades familiares que têm renda suficiente para pagar aluguel de imóveis cujo valor é muito superior à média dos imóveis próprios, significa que poderiam - dado que têm renda - ter imóvel, a análise da distribuição do estoque de riqueza imobiliária entre unidades familia-

3 Ver a respeito Reis et al. (2001), Munnell (1990), Holtz-Eakin (1994), Haughwout (2000), Neri (1999), Poterba (1992), Zabel (1999), Green \& Hendershott (1993), Wolff (2000, 2001), Spilerman (2000), Morais (2005).

4 Kelster (2000) destacou a expressiva diferença de propriedade imobiliária, segundo raça. Ver também Bourdieu et al. (2002).

5 A unidade de análise constitui-se na família principal de um domicílio.

6 Tratamos aqui família como sinônimo de domicílio, posto que as informações utilizadas referem-se ao domicílio. A aproximação é razoável, posto que do total de domicílios da PNAD 99\% são unifamiliares e o número médio de famílias por domicílio é 1,o8. 
res pode trazer elementos complementares aos estudos sobre desigualdade entre as famílias e indivíduos de renda, escolaridade e outros relevantes atributos.

A principal conclusão do estudo é que a distribuição do estoque de riqueza em residência sofreu ligeira melhora na "década", decorrente, em parte, de uma queda relativa da participação dos segmentos que mais detêm a propriedade de imóveis e, em parte, porque parcelas médias da sociedade tiveram melhoria de acesso à moradia própria. Obviamente que esse efeito pode também ser resultado de alterações da relação valor de aluguel e valor do imóvel7.

O artigo conta com quatro seções, além desta introdução. Na seção 1, são apresentadas informações básicas sobre a distribuição de residências no Brasil, entre 1995 e 2004, segundo categoria de uso. A seção 2 apresenta o modelo adotado na estimação ${ }^{8}$. A seção 3 apresenta os resultados obtidos e a seção 4 relata as principais conclusões do trabalho. Todas as tabelas e gráficos têm como fonte de dados as PNADs (Pesquisa Nacional por Amostra de Domicílios/IBGE) de diversos anos.

\section{Os imóveis no Brasil}

O total de imóveis no Brasil saltou de 38.474.478 em 1995, para 51.752 .528 em 2004. Isso corresponde a um crescimento de $34,51 \%$ no período e um crescimento anual médio de aproximadamente $3 \%$ ao ano. Nesse período, o número de imóveis cresceu 34\%, sendo 39,22\% (taxa média anual de $3,75 \%$ ) na zona urbana e apenas $11,12 \%$ (taxa média anual de $1,18 \%$ ) na zona rural9. A Tabela 1 apresenta esses dados, desagregados segundo situação urbana e rural.

\footnotetext{
7 Essa alteração pode decorrer de fatores diversos: a) alteração temporal, ou seja, todos os imóveis teriam a relação valor de aluguel/valor do imóvel alterada por alterações estruturais na oferta e demanda tanto no mercado de construção civil quanto no mercado de aluguel e também em função da taxa de juros da economia; b) alteração decorrente dos atributos físicos - como número de quartos e vagas de garagem, por exemplo - e de localização do imóvel, que refletem alterações urbanas de valorização ou desvalorização de espaços ou áreas da cidade.

8 Utilizamos o modelo proposto por Reis et al. (2001) com pequenas alterações.

9 Destaque-se o fato de que a taxa anual de crescimento entre 1995 e 2004 foi superior à observada entre 1991 e 1999 e isso se deve exclusivamente ao desempenho do setor urbano.
} 
TABELA 1- DISTRIBUIÇÃO DOS IMÓVEIS SEGUNDO OCUPAÇÃO, ZONA E TIPO DE OCUPAÇÃO - BRASIL - 1995-2004

\begin{tabular}{rlrrrrrr}
\hline Ano & & \multicolumn{1}{c}{ Próprios } & \multicolumn{1}{c}{ Alugados } & Cedido Particular & Cedido Empresa & \multicolumn{1}{c}{ Outros } & \multicolumn{1}{c}{ T o t a 1 } \\
\hline \multirow{2}{*}{1995} & Urbano & 22.594 .103 & 5.440 .387 & 2.568 .396 & 513.121 & 196.541 & 31.312 .548 \\
& Rural & 5.015 .872 & 129.894 & 713.812 & 1.276 .605 & 25.747 & 7.161 .900 \\
& Total & $\mathbf{2 7 . 6 0 9 . 9 7 5}$ & $\mathbf{5 . 5 7 0 . 2 8 1}$ & $\mathbf{3 . 2 8 2 . 2 0 8}$ & $\mathbf{1 . 7 8 9 . 7 2 6}$ & $\mathbf{2 2 2 . 2 8 8}$ & $\mathbf{3 8 . 4 7 4 . 4 7 8}$ \\
& (\%) & 71,76 & 14,48 & 8,53 & 4,65 & 0,58 & 100,00 \\
\hline \multirow{2}{*}{2004} & Urbano & 32.200 .701 & 7.816 .470 & 3.176 .885 & 397.679 & 202.831 & 43.794 .566 \\
& Rural & 5.944 .581 & 175.361 & 707.419 & 1.078 .444 & 52.157 & 7.957 .962 \\
& Total & $\mathbf{3 8 . 1 4 5 . 2 8 2}$ & $\mathbf{7 . 9 9 1 . 8 3 1}$ & $\mathbf{3 . 8 8 4 . 3 0 4}$ & $\mathbf{1 . 4 7 6 . 1 2 3}$ & $\mathbf{2 5 4 . 9 8 8}$ & $\mathbf{5 1 . 7 5 2 . 5 2 8}$ \\
& (\%) & 73,71 & 15,44 & 7,51 & 2,85 & 0,49 & 100,00 \\
\hline
\end{tabular}

Como se pode observar na Tabela 2, do acréscimo (33,99\%) de 13,28 milhões de imóveis no País, entre 1995 e 2004, praticamente 80\% ocorreu entre os imóveis próprios (10,54 milhões), com aumento de 10,35 milhões. Apesar desse expressivo aumento, foi entre os alugados que se observou a maior taxa de crescimento: passaram de 5,57 milhões em 1995 para 7,99 milhões em 2004, com taxa de crescimento de 43,5\% no período. Os imóveis próprios tiveram crescimento expressivo no período, especialmente na zona rural, com crescimento de quase $20 \%$ em seu quantitativo. Também os imóveis alugados apresentaram consistente crescimento em seu quantitativo, fato já identificado por Reis et al. (2001). Apesar de representarem cerca 15,5\% do total de imóveis, os alugados apresentam, como indicado na Tabela 3, uma tendência consistente de crescimento, tanto na zona rural quanto urbana. Fenômeno inverso ocorre para os demais tipos de imóveis, destacando-se a queda acentuada de imóveis cedidos por empresas na zona rural.

TABELA 2- EVOLUÇÃO DO NÚMERO DE IMÓVEIS POR CONDIÇÃO DE OCUPAÇÃO BRASIL - 1995-2004

\begin{tabular}{ccccc}
\hline \multirow{2}{*}{ Ano } & \multicolumn{3}{c}{ Condição de ocupação } & \multirow{2}{*}{ T o t a l } \\
& Próprios & Alugados & Demais & \\
\hline 1995 & 27.609 .975 & 5.570 .281 & 5.294 .222 & 38.474 .478 \\
2004 & 38.145 .282 & 7.991 .831 & 5.615 .415 & 51.752 .528 \\
\hline Variação 2004/95 & $38,2 \%$ & $43,5 \%$ & $6,1 \%$ & $34,5 \%$ \\
\hline
\end{tabular}


TABELA 3- DISTRIBUIÇÃO PERCENTUAL DOS IMÓVEIS SEGUNDO OCUPAÇÃO E ZONA CENSITÁRIA - BRASIL-1995-2004

\begin{tabular}{ccccccccc}
\hline $\begin{array}{c}\text { Situação } \\
\text { Censitária }\end{array}$ & Ano & Próprio & Alugado & Cedido Part & Cedido emp & Outra condição & Total \\
\hline \multirow{2}{*}{ Urbana } & 1995 & 72,16 & 17,37 & 8,20 & 1,64 & 0,63 & 100,00 \\
& 2004 & 73,53 & 17,85 & 7,25 & 0,91 & 0,46 & 100,00 \\
\hline \multirow{2}{*}{ Rural } & 1995 & 70,04 & 1,81 & 9,97 & 17,82 & 0,36 & 100,00 \\
& 2004 & 74,70 & 2,20 & 8,89 & 13,55 & 0,66 & 100,00 \\
\hline
\end{tabular}

\section{O modelo e os dados}

A distribuição do estoque de riqueza imobiliária dos imóveis residenciais permanentes não é uma informação diretamente disponível na PNAD. Logo, é necessário, primeiramente, estimar esse estoque e, em seguida, distribuí-lo entre as unidades familiares. O método que tem sido mais utilizado é o do estoque perpétuo. O método e suas variações, embora estime o estoque, não possibilita a identificação dos detentores da riqueza, inviabilizando a análise da sua distribuição ${ }^{10}$.

A alternativa proposta por Reis et al (2001) parte da hipótese de que o fluxo de rendimento derivado do estoque, uma proporção $\alpha$ deste, é distribuído uniformemente entre todo tipo de imóvel residencial, qualquer que seja sua localização e valor ${ }^{11}$. Portanto, se conhecemos a distribuição do fluxo, conhecemos a distribuição do estoque.

Dentre as informações primárias disponíveis na PNAD para cada domicílio estão a situação do imóvel, suas características físicas e sua localização, esta dada pelo setor censitário. No caso de imóveis alugados, há o valor do aluguel mensal pago (A). Como base nessas informações, é possível estimar para os imóveis alugados a contribuição de suas características físicas e de sua localização para determinação do valor de aluguel pago. Uma vez identificada a contribuição de cada atributo para o valor do aluguel é possível imputar para todos os demais imóveis (imóveis não alugados) o valor hipotético de um aluguel, caso fossem alugados. Uma vez que a relação entre valor de aluguel e valor do imó-

10 Ver a respeito Morandi (1995), Melazzo (1996).

11 É certamente uma hipótese forte. Há evidências de que essa relação varia no tempo, em função da taxa de juros, dos atributos físicos do imóvel e de sua localização. As duas primeiras indicam condições mais estruturais da economia e dos mercados de construção civil, de aluguel e de alocação entre ativos financeiros e imobiliários (Rebelo 1998) e parecem afetar todos os imóveis de forma relativamente homogênea. As duas seguintes estão intrinsecamente associadas a particularidades de cada imóvel, afetando diferentemente cada um deles, de modo a ter evidentes impactos sobre a distribuição de riqueza entre famílias. Informações empíricas acerca do valor de $\alpha$ indicam que oscila entre 0.0025 e 0.01 (Malpezzi 1991; Lucena 1985). Por simplicidade e dada a inexistência de informações que permitam utilizar diferentes valores dessa relação, optamos por manter, tal como feito por Reis et al., um valor constante, $\alpha=0.0075$. 
vel é constante, obtém-se o valor do estoque imobiliário residencial do País.

Uma outra informação primária disponível na PNAD é o rendimento, caso exista, que cada família recebe proveniente de aluguel (RA) de imóvel. Novamente, com base na hipótese de constância da relação valor de aluguel/valor do imóvel, obtém-se o valor do imóvel que a família tem - e que está alugado.

Finalmente, somando-se o valor imputado do imóvel próprio não alugado ao valor do estoque imobiliário derivado da renda de aluguel, chega-se à distribuição familiar do estoque de riqueza imobiliária residencial.

Feitas essas considerações, passemos à descrição do modelo.

\subsection{O modelo de estimação}

Assume-se que o valor de aluguel de um imóvel é função de suas características físicas e de sua localização. Assim, $\mathrm{A}=f(\mathrm{X}, \mathrm{Z})$, onde $\mathrm{X}$ é uma matriz de atributos físicos e $\mathrm{Z}$ uma matriz de atributos associados à sua localização. Admitindo, como feito por Reis et al. (2001), que o imóvel é um bem heterogêneo, seu aluguel (A) pode ser decomposto nos preços de suas características ${ }^{12}$.

Uma vez estimados os coeficientes (preços) de cada uma das características determinantes do aluguel, pode-se utilizá-los para imputar o valor do aluguel das residências próprias. Para tanto, é necessário, inicialmente, estimar a regressão que associa o logaritmo do aluguel aos atributos dos imóveis. Os atributos físicos foram classificados em quatro grandes grupos: (i) tipo de moradia (casa, apartamento, etc.); (ii) estrutura de construção (material utilizado nas paredes e tetos); (iii) dimensão do imóvel (número de cômodos); (iv) acesso aos serviços de infra-estrutura.

O efeito localização espacial dos imóveis foi representado por dois conjuntos de informação: a) o primeiro conjunto capta o efeito localização associado ao porte do município em que o imóvel está situado. A hipótese aqui é que o tamanho e a complexidade produtiva dos 
municípios afetam o valor do aluguel ${ }^{13}$; b) o segundo conjunto capta o efeito localização associado à vizinhança do imóvel, ou seja, ao seu entorno mais próximo. Para o primeiro conjunto informativo, foram criadas duas variáveis dummies que caracterizam o porte do município $^{14}$ assim definidas: uma para municípios auto-representativos; e outra, para municípios da Região Metropolitana (de fato estes são os demais municípios da Região Metropolitana). Para o segundo, foram criadas variáveis que captam o efeito localização de vizinhança que são: a renda mediana do setor censitário e a densidade de moradores por cômodo no setor censitário.

Feitas essas considerações o modelo de estimação é expresso por:

$$
\ln \left(A_{i}\right)=X_{i} \beta+Z \delta+u_{i s}, \quad i=1, \ldots, N \text { e } s=1, \ldots, S \quad(1)^{15},
$$

O modelo linear foi estimado usando como base de dados todos os imóveis alugados disponíveis na PNAD. O valor esperado do aluguel é dado, sob hipótese de termo aleatório normalmente distribuído, por: $\quad \mathrm{E}\left(A_{i}\right)=\exp \left[\mathrm{E}\left[\ln \left(A_{i}\right)\right]\right.$

Estimados os vetores de coeficientes $\beta$ e $\delta$, utilizamos os mesmos nos correspondentes atributos dos imóveis não alugados, de modo a obter o valor do aluguel do imóvel i $\left(A I_{i}\right)$, caso este fosse alugado. Assim:

$$
A I_{i}=\exp \left[\left(X \hat{\beta}^{+Z} \hat{\delta}\right)\right]
$$

Uma vez feito o processo de imputação, pode-se obter o Valor Total de Aluguéis (VAT), que será a soma dos aluguéis imputados (AI) referente aos imóveis não alugados - com os aluguéis efetivamente pagos (AT) - referente aos imóveis alugados. O valor correspondente ao estoque de capital residencial (EKR) é obtido com o uso de $\alpha$. Nesse caso, tem-se:

13 A hipótese foi confirmada pelos resultados.

14 A amostra da PNAD é composta por dois estratos: o auto-representativo, que inclui municípios que pelo seu "peso" demográfico relativo sempre estão presentes na amostra e os não-autorepresentativos, que participam da amostra segundo sorteio e sua probabilidade é dada por sua população no total da UF. Os primeiros, adicionados de parcela dos segundos, compõem as Regiões Metropolitanas; o restante do segundo grupo, compõe o interior de cada UF. Para maiores detalhes ver, para os respectivos anos, Metodologia da PNAD, IBGE.

15 O modelo utilizado aqui tem uma pequena diferença em relação ao modelo utilizado por Reis et al (2001). Lá, definiu-se o termo aleatório como uma combinação linear de dois elementos e fez-se a estimação em dois estágios. Para maiores detalhes ver Reis et al. (2001: 9-11). 


$$
\begin{aligned}
& \mathrm{VAT}=\mathrm{AI}+\mathrm{AT} \\
& \mathrm{EKR}=\mathrm{VAT} / \alpha
\end{aligned}
$$

A última etapa do processo é a alocação do estoque de riqueza a cada unidade familiar. Assim, a partir da informação sobre recebimento de aluguéis e partindo-se da hipótese de que a relação $\alpha$ entre o preço do aluguel e o preço do imóvel é constante, transformou-se essa renda de aluguel (RA) recebida pelas famílias em estoque de riqueza imobiliária (RA/ $\alpha$ ) da família. O estoque total de riqueza de cada família será dado pela soma da riqueza derivada da renda de aluguel com o valor do imóvel caso a residência seja própria (EKRP). Assim, o estoque de riqueza em imóveis residenciais para cada unidade familiar $i$ (ERI $i$ ) é dado por ${ }^{16}$ :

$$
\mathrm{ERI} i=(\mathrm{RA} i / \alpha)+\mathrm{EKRP} i
$$

\subsection{Dados utilizados}

Os dados aqui utilizados - aluguéis mensais pagos, rendimento mensal proveniente de aluguel, os atributos físicos dos imóveis e as variáveis proxy para a localização do imóvel são extraídos da Pesquisa Nacional por Amostra de Domicílio para os dois anos analisados e referem-se exclusivamente aos imóveis residenciais que estão classificados nas PNADs como "domicílios particulares permanentes"17. Um domicílio é particular permanente se no momento do levantamento de dados pelo IBGE "servia de moradia a uma, duas, ou no máximo cinco famílias”, sendo específico para fim residencial.

\footnotetext{
16 Esse procedimento permite captar a distribuição do estoque dos imóveis próprios e alugados, mas não os imóveis cedidos por empregador, e os cedidos por particulares e os classificados como "outros". Os primeiros não estão contemplados em nosso objeto de estudo, mas os imóveis cedidos por particulares, sim. Como pode ser visto na Tabela 1, eles representavam 8,5\% dos imóveis em $1995 \mathrm{e}$ 7,5\% em 2004. Aqueles classificados como outros têm participação desprezível. Dentre os domicílios cedidos, $91 \%$ são casas; $88,3 \%$ possuem parede de alvenaria; $77,6 \%$ possuem material predominante na cobertura telha e 20,2\% laje de concreto; 90,7\% possuem água canalizada; $95 \%$ possuem banheiro ou sanitário e $86,5 \%$ possuem lixo domiciliar coletado diretamente e apenas $36 \%$ dos imóveis cedidos são localizados nas regiões metropolitanas.

17 Ficam excluídos, portanto, os imóveis não residenciais como os classificados como "domicílios coletivos" (hotéis, pensões, recolhimentos, asilos, orfanatos, conventos, penitenciárias, quartéis, postos militares, navios, alojamentos de trabalhadores, etc) e os classificados como "domicílios particulares improvisados" (aqueles localizados em estabelecimentos industriais e comerciais, embarcações, carroças, vagões de estrada de ferro, tendas, barracas, grutas, etc).
} 
As variáveis utilizadas foram agrupadas em cinco grupos, segundo atributos de caracterização física do imóvel e de localização e vizinhança. São eles: tipo de moradia: caracteriza se a residência é casa, apartamento ou cômodo, além da sua localização (exceto para cômodo); estrutura de construção: caracteriza o material de construção utilizado nas paredes e na cobertura da construção; dimensão do imóvel: caracteriza o tamanho do imóvel pelo número de dormitórios e dos demais cômodos; serviços de infra-estrutura: caracteriza a infra-estrutura disponível ao imóvel, incluindo abastecimento de água, instalações sanitárias, coleta de lixo e iluminação; e localização e vizinhança: trata-se de um conjunto de variáveis dummies que visam caracterizar as condições de habitabilidade do local onde está localizado o imóvel e sua vizinhança e também o porte do município em que o imóvel está localizado, com intuito de controlar eventuais diferenças existentes no aluguel residencial em cidades de portes diferentes ${ }^{18}$. A Tabela 4 resume essas informações.

TABELA 4- DISTRIBUIÇÃO DOS DOMICÍLIOS URBANOS SEGUNDO ATRIBUTOS DO IMÓVEL - BRASIL - 1995/2004

\begin{tabular}{|c|c|c|c|c|}
\hline \multirow{2}{*}{$\begin{array}{l}\text { Grupo de } \\
\text { variáveis }\end{array}$} & \multicolumn{2}{|l|}{ Atributos do imóvel } & \multicolumn{2}{|c|}{ Domicílios urbanos } \\
\hline & & & 1995 & 2004 \\
\hline \multirow{4}{*}{ 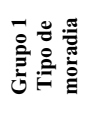 } & \multirow[t]{4}{*}{ Tipo de imóvel } & Casa & 88,01 & 87,65 \\
\hline & & Apartamento & 11,12 & 11,85 \\
\hline & & Outro & 0,90 & 0,50 \\
\hline & & Total & 100,00 & 100,00 \\
\hline \multirow{8}{*}{ 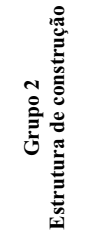 } & \multirow[t]{4}{*}{ Material das paredes externas } & Alvenaria & 87,93 & 91,31 \\
\hline & & Madeira aparelhada & 9,67 & 7,20 \\
\hline & & Outros materiais & 2,40 & 1,49 \\
\hline & & Total & 100,00 & 100,00 \\
\hline & \multirow[t]{4}{*}{ Material do telhado } & Telha & 76,65 & 73,78 \\
\hline & & laje de concreto & 21,19 & 24,83 \\
\hline & & Outros materiais & 2,16 & 1,39 \\
\hline & & Total & 100,00 & 100,00 \\
\hline
\end{tabular}

18 A hipótese é que em centros maiores existe melhor infra-estrutura não captada nas características das residências, como a maior presença de shoppings centers, supermercados, cinemas, teatros e outros tipos de serviços e lazer. 
TAFNER, P.; CARVALHO, M. Evolução da distribuição familiar...

\begin{tabular}{|c|c|c|c|c|}
\hline \multirow{12}{*}{ 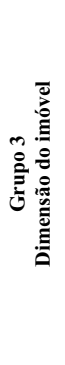 } & \multirow[t]{3}{*}{ Número de dormitórios ${ }^{19}$} & 1 & 32,3 & 34,4 \\
\hline & & 2 & 43,4 & 43,8 \\
\hline & & 3 ou mais & 24,3 & 21,8 \\
\hline & $\therefore$ & Total & 100,0 & 100,0 \\
\hline & \multirow[t]{5}{*}{ Número de outros cômodos } & 0 ou 1 & 8,4 & 4,9 \\
\hline & & 2 & 16,3 & 14,7 \\
\hline & & 3 & 30,8 & 31,6 \\
\hline & & 4 ou mais & 44,5 & 48,8 \\
\hline & & Total & 100,0 & 100,0 \\
\hline & \multirow[t]{3}{*}{ Existência de banheiro ou sanitário } & Sim & 95,6 & 98,1 \\
\hline & & Não & 4,4 & 1,9 \\
\hline & & Total & 100,0 & 100,0 \\
\hline \multirow{18}{*}{ 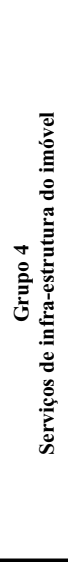 } & \multirow[t]{4}{*}{ Proveniência da água } & Rede geral & 95,39 & 94,98 \\
\hline & & Poço ou nascente & 4,52 & 4,9 \\
\hline & & Outra/ignorado & 0,09 & 0,12 \\
\hline & & Total & 100,00 & 100,00 \\
\hline & \multirow[t]{6}{*}{ Forma de escoadouro } & Rede de esgoto & 50,39 & 57,14 \\
\hline & & Fossa rudimentar & 21,20 & 17,18 \\
\hline & & Fossa não ligada à rede & 11,03 & 12,21 \\
\hline & & Fossa ligada à rede & 12,74 & 10,02 \\
\hline & & Outra/ignorado & 4,64 & 3,45 \\
\hline & & Total & 100,00 & 100,00 \\
\hline & \multirow[t]{5}{*}{ Destino do lixo } & Coletado diretamente & 79,33 & 88,3 \\
\hline & & Coletado indiretamente & 7,37 & 7,98 \\
\hline & & Queimado ou enterrado & 6,41 & 2,24 \\
\hline & & Outra/ignorado & 6,89 & 1,48 \\
\hline & & Total & 100,00 & 100,00 \\
\hline & \multirow[t]{3}{*}{ Forma de iluminação } & Elétrica (rede,gerador, solar) & 98,58 & 99,58 \\
\hline & & Outra/ignorado & 1,43 & 0,42 \\
\hline & & Total & 100,00 & 100,00 \\
\hline \multirow{16}{*}{ 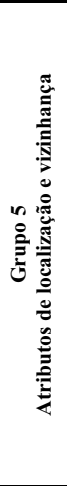 } & \multirow[t]{4}{*}{ Ln da mediana da renda } & Casa & 6,23 & 6,79 \\
\hline & & Apartamento & 7,71 & 7,81 \\
\hline & & Outro & 6,05 & 6,58 \\
\hline & & Total & 6,34 & 6,91 \\
\hline & \multirow[t]{4}{*}{ Densidade de moradores } & Casa & 2,11 & 1,94 \\
\hline & & Apartamento & 1,68 & 1,61 \\
\hline & & Outro & 2,23 & 2,12 \\
\hline & & Total & 2,06 & 1,9 \\
\hline & \multirow[t]{4}{*}{ Idade mediana dos moradores do setor } & Casa & 25,1 & 28,1 \\
\hline & & Apartamento & 31,8 & 34,2 \\
\hline & & Outro & 24,6 & 26 \\
\hline & & Total & 25,8 & 28,8 \\
\hline & \multirow[t]{4}{*}{ Proporção de brancos no setor } & Casa & 0,6 & 0,54 \\
\hline & & Apartamento & 0,78 & 0,72 \\
\hline & & Outro & 0,48 & 0,38 \\
\hline & & Total & 0,62 & 0,56 \\
\hline
\end{tabular}

19 Deve-se chamar a atenção para o fato de que o IBGE, na PNAD 2003, coletou informações sobre área construída do imóvel, valor estimado e existência de garagem. Lamentavelmente, essas perguntas não foram repetidas em 2004. 


\subsection{Os aluguéis pagos}

Como apresentado na Tabela 5, o número de imóveis alugados cresceu $42,84 \%$ entre 1995 e 2004, com uma taxa de crescimento médio anual de 4,04\%. O valor médio do aluguel pago passou de $\mathrm{R} \$ 186,46$ para $\mathrm{R} \$$ 239,14, com elevação de $28,25 \%$. Apesar desse crescimento reduzido, a variação da mediana foi de $66,67 \%$, indicando que elevação mais expressiva ocorreu nos valores mais reduzidos.

TABELA 5- ESTATÍSTICAS DESCRITIVAS DO VALOR DE ALUGUEL PAGO DOMICÍLIOS URBANOS - BRASIL - 1995-2004

\begin{tabular}{lcr}
\hline & \multicolumn{2}{c}{ Aluguel mensal (R\$) } \\
\cline { 2 - 3 } Estatísticas & 1995 & \multicolumn{1}{c}{2004} \\
\hline $\mathrm{N}^{*}$ & 5.412 .724 & 7.792 .662 \\
Média & 186,46 & 239,14 \\
Mediana & 120,00 & 200,00 \\
Moda & 100,00 & 200,00 \\
Desvio-padrão & 192,33 & 207,50 \\
\hline
\end{tabular}

(*) Em 2004 existiam 23.808 domicílios alugados sem declaração do valor do aluguel. Em 1995 eram 27.663 sem declaração.

A Tabela 6 apresenta os valores médios e medianos de aluguel para os anos de 1995 e 2004, segundo algumas características dos imóveis. Observe que, com exceção dos imóveis com 5 cômodos servindo de dormitório, todos os imóveis apresentam crescimento no valor nominal médio de aluguel. Observe ainda, que os maiores crescimentos ocorreram nos imóveis situados no interior do País, ou pelo menos fora das grandes cidades, nas casas e nos imóveis de menor dimensão (1 e 2 dormitórios).

Deve-se destacar que para todas as variáveis o valor mediano do aluguel apresenta crescimento superior ao observado para o valor médio, indicando que foram os imóveis de menor valor de aluguel os que tiveram crescimento mais expressivo no período. 
TABELA 6- ALUGUEL PAGO (R\$) SEGUNDO CARACTERÍSTICAS DOS DOMICÍLIOS - BRASIL - 1995-2004

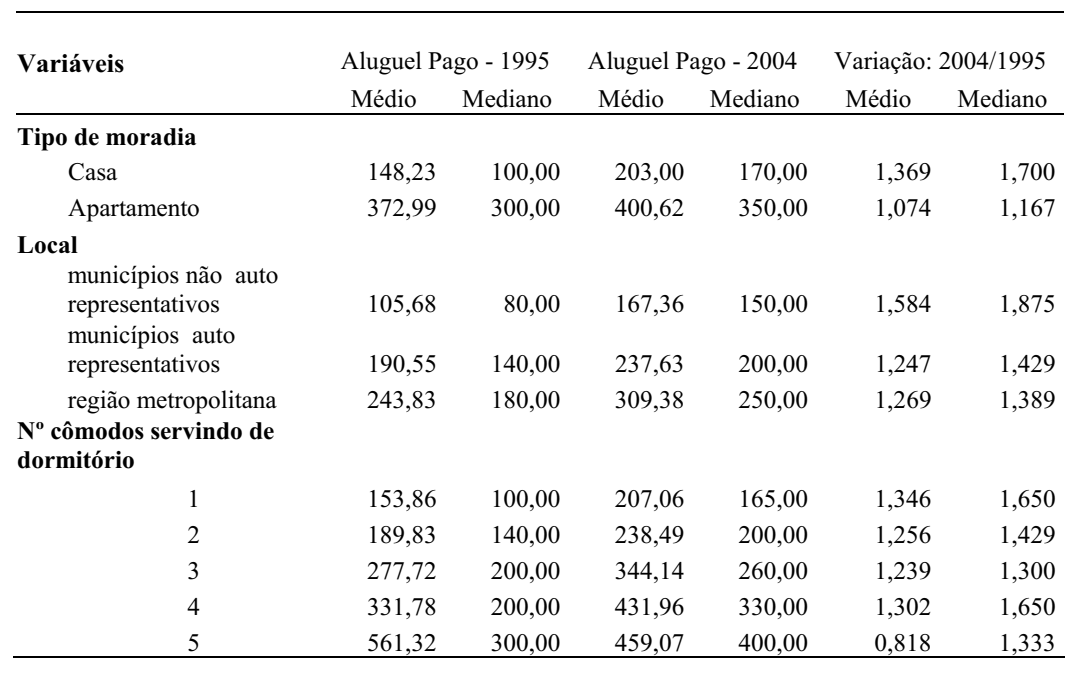

\section{Resultados obtidos}

Na presente seção, são apresentadas as estimativas dos coeficientes, do estoque de capital em imóveis residenciais e da riqueza imobiliária em poder das famílias e sua distribuição.

\subsection{Os coeficientes estimados e os demais resultados das regressões}

Como já dito, foram estimadas duas regressões, uma para cada ano analisado. Os resultados sintéticos estão apresentados na Tabela 7 e deixam evidente que a qualidade do ajuste é bastante satisfatória. A análise dos coeficientes mostra que das 24 variáveis utilizadas no modelo, 19 foram significativas e com os sinais corretos para os dois períodos; sendo as mesmas 19 variáveis significativas e com o sinal esperado para 1995. Para 2004, 22 variáveis mostraram-se significativas e com os sinais corretos ${ }^{20}$ e para ambos os períodos 15 variáveis mostraram-se significativas a $1 \%$. Em ambas as regressões o intercepto apresentou sinal negativo.

O conjunto das 14 variáveis significativas e com sinais estáveis incorpora características de todos os grupos de variáveis. $\mathrm{O}$ apartamento que, progres-

20 Isso se deve ao fato de que, em 1995, o alinhamento de preços relativos pós-plano Real ainda estava em curso, enquanto que, em 2004, os preços já estavam alinhados e a inflação em níveis muito reduzidos se comparados a 1995 . 
sivamente vai tendo maior presença entre os imóveis, é significativo nos dois períodos - e, em ambos, o é a 1\% - e apresenta elevado valor do coeficiente. Também a dimensão do imóvel, representada pelas variáveis número de dormitórios e número de outros cômodos (além dos dormitórios), são também significativos em ambos os períodos e, também a 1\%, além de terem ambos coeficientes elevados. As variáveis representativas da infra-estrutura, com a exceção de sanitário com fossa rudimentar (uma das duas variáveis não significativas para os dois anos), são todas significativas em ambos os períodos. Destaque-se o fato de que dentre as significativas, à exceção de iluminação elétrica, mostraram-se significativas a 1\% nos dois anos analisa$\operatorname{dos}^{21}$. Por fim, todas as variáveis designativas de localização e vizinhança revelaram-se significativas em ambos os períodos e, sempre, a $1 \%$.

TABELA 7- COEFICIENTES ESTIMADOS E NÍVEL DE SIGNIFICÂNCIA BRASIL - 1995-2004

\begin{tabular}{|c|c|c|c|c|c|}
\hline \multirow[b]{2}{*}{ Grupo } & \multirow[b]{2}{*}{ Variável } & \multicolumn{2}{|c|}{1995} & \multicolumn{2}{|c|}{2004} \\
\hline & & Coeficiente & Significância & Coeficiente & Significância \\
\hline \multirow{8}{*}{$\begin{array}{l}\text { Tipo de } \\
\text { moradia e } \\
\text { estrutura de } \\
\text { construção }\end{array}$} & (Constante) & $-0,62122$ & 0,0002 & $-0,3113$ & 0,0156 \\
\hline & Apto $^{*}$ & 0,25460 & 0,0000 & 0,1205 & 0,0000 \\
\hline & Parede de alvenaria & 0,36616 & 0,0000 & 0,1609 & 0,0243 \\
\hline & Parede de madeira & 0,16530 & 0,0597 & $-0,0930$ & 0,0643 \\
\hline & $\mathrm{e}^{\text {Parede de taipa }}$ & 0,27026 & 0,0340 & $-0,4566$ & 0,0000 \\
\hline & Cobertura de laje ${ }^{*}$ & 0,17989 & 0,0261 & 0,2605 & 0,0000 \\
\hline & Cobertura de telha & 0,06161 & 0,4408 & 0,1781 & 0,0017 \\
\hline & Cobertura de zinco & 0,03460 & 0,7294 & 0,1683 & 0,0156 \\
\hline \multirow{4}{*}{$\begin{array}{l}\text { Dimensão } \\
\text { do imóvel }\end{array}$} & $\begin{array}{l}\text { Num de outros } \\
\text { cômodos }\end{array}$ & 0,12330 & 0,0000 & 0,1115 & 0,0000 \\
\hline & Num de dormitórios ${ }^{*}$ & 0,17256 & 0,0000 & 0,1533 & 0,0000 \\
\hline & Existência de banheiro & 0,09542 & 0,0693 & 0,2590 & 0,0000 \\
\hline & $\begin{array}{l}\text { Água canalização } \\
\text { interna* }\end{array}$ & 0,26604 & 0,0000 & 0,2566 & 0,0000 \\
\hline \multirow{6}{*}{$\begin{array}{l}\text { Serviços de } \\
\text { infra- } \\
\text { estrutura } \\
\text { do imóvel }\end{array}$} & Sanitário rede geral ${ }^{*}$ & 0,19167 & 0,0000 & 0,1177 & 0,0000 \\
\hline & Sanitário fsrp ${ }^{*}$ & 0,10620 & 0,0043 & 0,0825 & 0,0017 \\
\hline & Sanitário fsse ${ }^{*}$ & 0,15228 & 0,0001 & 0,0903 & 0,0005 \\
\hline & Sanitário frud & 0,00513 & 0,8890 & $-0,0417$ & 0,0986 \\
\hline & $\begin{array}{l}\text { Lixo coletado } \\
\text { diretamente }^{*}\end{array}$ & 0,26347 & 0,0000 & 0,2241 & 0,0000 \\
\hline & $\begin{array}{l}\text { Lixo coletado } \\
\text { indiretamente }\end{array}$ & 0,14743 & 0,0000 & 0,1690 & 0,0000 \\
\hline \multirow{7}{*}{$\begin{array}{l}\text { Localização } \\
\text { e } \\
\text { vizinhança }\end{array}$} & Ilum_elétrica & 0,22785 & 0,0171 & 0,2886 & 0,0017 \\
\hline & Ln mediana renda & 0,39924 & 0,0000 & 0,3902 & 0,0000 \\
\hline & P_de moradores & 0,13621 & 0,0000 & 0,0973 & 0,0000 \\
\hline & D_auto* & 0,25779 & 0,0000 & 0,2126 & 0,0000 \\
\hline & D_metropolitana & 0,38660 & 0,0000 & 0,3617 & 0,0000 \\
\hline & Mediana_idade & 0,00388 & 0,0010 & 0,0074 & 0,0000 \\
\hline & P brancos ${ }^{*}$ & 0,22939 & 0,0000 & 0,3345 & 0,0000 \\
\hline & $\mathbf{R}^{2}$ & \multicolumn{2}{|c|}{0,633} & \multicolumn{2}{|c|}{0,669} \\
\hline & $\mathbf{R}^{2}$ ajustado & \multicolumn{2}{|c|}{0,632} & \multicolumn{2}{|c|}{0,669} \\
\hline & F & \multicolumn{2}{|c|}{633,1} & \multicolumn{2}{|c|}{1369,7} \\
\hline
\end{tabular}

21 São elas: água, canalização interna, instalação sanitária ligada à rede geral, fossa séptica ligada à rede pluvial, fossa séptica sem escoadouro, fossa rudimentar, lixo coletado diretamente e lixo coletado indiretamente. 
Na Tabela 8, é apresentada a contribuição marginal da qualidade do ajuste de cada grupo de variável. Como se pode observar, o grupo que tem maior contribuição marginal é o grupo 5 "atributos de localização e vizinhança”, e em seguida, o grupo 2 "dimensão do imóvel". Observe também que a contribuição marginal do primeiro grupo cresce $25 \%$ entre 1995 e 2004. Isso pode ser um indicativo de que os imóveis ao se tornarem mais homogêneos ${ }^{22} \mathrm{em}$ termos de qualidade de construção e de infra-estrutura - como conseqüência da uniformização tecnológica da indústria de construção civil - têm seus valores definidos por sua localização e por seu tamanho ${ }^{23}$.

TABELA 8. CONTRIBUIÇÃO MARGINALÀ QUALIDADE DE AJUSTE DOS GRUPOS VARIÁVEIS INDEPENDENTES - BRASIL - 1995 - 2004

\begin{tabular}{lcccccc}
\hline Grupo de variáveis & \multicolumn{3}{c}{$\mathbf{1 9 9 5}$} & \multicolumn{3}{c}{$\mathbf{2 0 0 4}$} \\
\hline & $\mathbf{R}^{\mathbf{2}}$ & Diferença & Contribuição & $\mathbf{R}^{\mathbf{2}}$ & Diferença & Contribuição \\
\hline Moradia e estrutura de construção & 0,610 & 0,023 & $10,31 \%$ & 0,655 & 0,014 & $4,53 \%$ \\
Dimensão & 0,564 & 0,069 & $30,94 \%$ & 0,580 & 0,089 & $28,80 \%$ \\
Serviços de infra-estrutura & 0,613 & 0,020 & $8,97 \%$ & 0,656 & 0,013 & $4,21 \%$ \\
Localização e vizinhança & 0,522 & 0,111 & $49,78 \%$ & 0,476 & 0,193 & $62,46 \%$ \\
\hline Com todas & 0,633 & 0,223 & $100,00 \%$ & 0,669 & 0,309 & $100,00 \%$ \\
\hline
\end{tabular}

\subsection{A imputação do aluguel para os imóveis próprios}

Uma vez obtidos os coeficientes para os dois anos analisados, utilizamos esses para imputar o valor hipotético de aluguel para os imóveis próprios, caso estes fossem alugados. Preliminarmente, algumas considerações devem ser feitas com o intuito de avaliarmos possíveis diferenças entre imóveis próprios e alugados.

A Tabela 9 apresenta estatísticas dos atributos dos imóveis distinguindo-os entre alugados e próprios. Como se pode observar, em termos médios, os imóveis alugados têm qualidade superior à dos imóveis próprios. Em primeiro lugar, enquanto menos de $10 \%$ dos imóveis próprios são apartamentos (9,39\% em 2004 e 7,23\% em 1995), esse percentual sobe para praticamente $20 \%$ entre os aluga-

$22 \mathrm{E}$ isso pode ocorrer por duas razões: em primeiro lugar porque a construção de imóveis concentrase progressivamente nas incorporadoras e construtoras que tendem, por razões de escala, a padronizar a construção; em segundo lugar porque imóveis mais antigos, sobretudo casas e edifícios pequenos, tendem a ser substituídos por novas unidades que são produzidas pelas incorporadoras, o que reforça o efeito de homogeneização. O efeito é a ampliação do peso relativo da localização e do tamanho do imóvel na determinação de preço do imóvel, como se observa na Tabela 6 .

23 Usando-se o desvio-padrão como medida de homogeneidade técnica dos imóveis, observa-se que a dispersão do número de cômodos que servem de dormitório passou de 0,85 em 1995, para 0,82 em 2004; a dispersão do número de outros cômodos passou de 2,03 em 1995, para 1,99 em 2004. 
dos (19,06\% em 2004 e 17,94\% em 1995). Em relação aos atributos de material e estrutura de construção e de infra-estrutura do imóvel, observa-se que ${ }^{24}$ :

a) a alvenaria é o material de parede em 93\% dos imóveis alugados e em $90 \%$ dos próprios;

b) o material predominante no telhado é telha em ambos, porém $30 \%$ dos imóveis alugados possuem laje de concreto, enquanto $23 \%$ dos próprios possuem esse mesmo tipo de cobertura;

c) a oferta de água canalizada para os imóveis alugados é $96,74 \%$ enquanto que para os imóveis próprios é 94,86\%;

d) cerca de $65 \%$ dos imóveis alugados possuem esgotamento sanitário ligado à rede geral, enquanto apenas $55 \%$ dos imóveis próprios possuem esse tipo de esgotamento; e

e) cerca de $90 \%$ dos imóveis alugados possuem lixo coletado diretamente, enquanto $87 \%$ dos imóveis próprios possuem esse serviço público.

Observe, ainda, que houve convergência na distribuição espacial de imóveis próprios e alugados (igual incidência nas áreas metropolitanas) e que o imóvel próprio é ligeiramente maior quando se compara o número de dormitórios. A conseqüência da diferença de qualidade é que o valor médio de aluguel imputado para esses imóveis é inferior ao valor do aluguel que é pago pelos imóveis que estão de fato alugados.

24 Obviamente, a diferença de alguns dos valores aqui apresentados não é estatisticamente significativa, mas chama atenção que mesmo quando estatisticamente iguais, os valores pontuais são sempre superiores para os imóveis alugados. 
TABELA 9- CARACTERÍSTICAS DOS DOMICÍLIOS POR CONDIÇÃO DE PROPRIEDADE - BRASIL - 1995-2004

\begin{tabular}{|c|c|c|c|c|c|}
\hline \multirow[b]{2}{*}{ Característica } & & \multicolumn{2}{|c|}{$\begin{array}{c}\text { \% de domicílios - } \\
1995\end{array}$} & \multicolumn{2}{|c|}{$\%$ de domicílios -2004} \\
\hline & & Próprio & Alugado & Próprio & Alugado \\
\hline \multirow[t]{3}{*}{ Tipo de domicílio } & & 100 & 100 & 100 & 100 \\
\hline & Casa & 92,77 & 79,65 & 90,75 & 79,91 \\
\hline & Apartamento & 7,23 & 17,94 & 9,39 & 19,06 \\
\hline \multirow[t]{3}{*}{ Material da parede } & & 100 & 100 & 100 & 100 \\
\hline & Alvenaria & 86,39 & 90,6 & 90,86 & 93,11 \\
\hline & Outro material & 13,61 & 9,4 & 9,14 & 6,89 \\
\hline \multirow[t]{4}{*}{ Material do telhado } & & 100 & 100 & 100 & 100 \\
\hline & Telha & 78,77 & 71,92 & 75,13 & 69,23 \\
\hline & Laje de concreto & 18,72 & 26,6 & 23,38 & 29,86 \\
\hline & Outro material & 2,51 & 1,48 & 1,49 & 0,91 \\
\hline \multirow[t]{3}{*}{ Água canalizada? } & & 100 & 200 & 100 & 200 \\
\hline & Sim & 88,83 & 91,17 & 94,86 & 96,74 \\
\hline & Não & 11,17 & 8,83 & 5,14 & 3,26 \\
\hline \multirow[t]{3}{*}{ Esgotamento sanitário } & & 100 & 100 & 100 & 100 \\
\hline & Rede geral & 46,55 & 59,92 & 54,68 & 65,19 \\
\hline & Não rede geral & 53,45 & 40,08 & 45,32 & 34,81 \\
\hline \multirow[t]{3}{*}{ Lixo coletado diretamente? } & & 100 & 100 & 100 & 100 \\
\hline & Sim & 76,77 & 86,2 & 87,72 & 91,16 \\
\hline & Não & 23,23 & 13,8 & 12,28 & 8,84 \\
\hline \multirow[t]{3}{*}{ Iluminação elétrica } & & 100 & 100 & 100 & 100 \\
\hline & Sim & 98,47 & 99,42 & 99,6 & 99,85 \\
\hline & Não & 1,53 & 0,58 & 0,4 & 0,15 \\
\hline \multirow[t]{3}{*}{ Região Metropolitana } & & & & 100 & 100 \\
\hline & Sim & 38,14 & 42,96 & 37,78 & 37,54 \\
\hline & Não & 61,86 & 57,04 & 62,22 & 62,46 \\
\hline \multicolumn{6}{|l|}{ Cômodos dormitórios } \\
\hline & $\mathrm{N}^{\circ}$ médio & 2,07 & 1,87 & 2,01 & 1,77 \\
\hline
\end{tabular}

\subsection{O valor do estoque de capital em residência}

Na presente seção, vamos transformar o aluguel (observado e imputado) em valor dos imóveis, por meio da relação $\alpha$, anteriormente definida. A hipótese adotada em relação ao $\alpha$ é que ele seja constante em suas três dimensões: no tempo, no espaço e segundo o tipo do imóvel. Se estivéssemos considerando períodos com elevada inflação, como tivemos até 1994, essa hipótese seria certamente muito restritiva, comprometendo seriamente a confiabilidade das estimativas. Apesar de inexistir o problema inflacionário, há, em 1999, uma quebra estrutural na vida econômica do País, com a mudança do regime cambial e uma súbita desvalorização cambial de 56\%. Certamente, naquele momento, o valor de $\alpha$ se alterou, pois parte da desvalorização cambial foi incorporada aos preços dos imóveis, sobretudo naqueles mais valorizados. No entanto, parte desses imóveis que têm elevado valor e 
que servem como reserva de valor e/ou como ativo de proteção ao risco, sobretudo em momentos de instabilidade, estão fora do mercado de aluguéis. Além disso, uma vez adotado o câmbio flutuante, as oscilações bruscas tendem a diminuir, fazendo com que oscilações no valor do imóvel sejam menos prováveis. Por fim, como estamos comparando 1995 e 2004, ano em que houve apreciação suave do câmbio, a hipótese de constância de $\alpha$ não parece comprometer as estimativas. Na Tabela 10 são apresentados os valores de estoque de capital imobiliário residencial considerando-se diversos deflatores.

TABELA 10- ESTOQUE DE CAPITAL EM RESIDÊNCIAS A PREÇOS CORRENTES E CONSTANTES - BRASIL - 1995-2004 R\$ BILHÕES DE 2000 - $(\alpha=0,0075)$

\begin{tabular}{lrrr}
\hline \multicolumn{1}{c}{ Valor Nominal e Deflacionado } & $\mathbf{1 9 9 5}$ & $\mathbf{1 9 9 9}$ & $\mathbf{2 0 0 4}$ \\
\hline Valor Nominal & 803,00 & $1.074,76$ & $1.543,68$ \\
DI - Pib & $1.225,62$ & $1.164,56$ & $1.048,42$ \\
INPC - aluguel & $1.616,81$ & $1.143,31$ & $1.467,67$ \\
Câmbio & $1.614,59$ & $1.083,93$ & $1.137,17$ \\
\hline
\end{tabular}

FONTE: PNAD's diversos anos

Como se observa na Tabela 10, o estoque de capital residencial apresenta redução entre 1995 e 1999, mas a magnitude de redução varia bastante em função do deflator que se utiliza. A perda de valor quando o deflator é o câmbio é a mais acentuada, revelando defasagem temporal no ajustamento do preço de imóveis diante do choque de câmbio. Os preços dos imóveis tendem, em certa medida e com alguma defasagem, a acompanhar a variação do dólar, dependendo obviamente das condições de compra e venda no mercado de imóveis, da oferta de crédito e da percepção de incerteza na economia ${ }^{25}$.

A recuperação do valor do estoque em 2004, quando se utilizam os deflatores INPC-aluguel ou câmbio, revelam respectivamente a contínua redução da renda do trabalho no período e a gradual apreciação do câmbio. Por outro lado, quando se utiliza o deflator implícito do PIB, observa-se ainda redução, provavelmente como conseqüência da pressão de preços de 2003. De toda forma, esses resultados indicam que qualquer análise temporal sobre a evolução do estoque de riqueza da economia deve levar em conta a complexida-

25 Como os aluguéis estão sujeitos a regras contratuais e ao nível de renda da economia, ajustandose com velocidade menor do que os preços de imóveis, a conseqüência é oscilação no valor de $\alpha$, o que viola nossa hipótese de trabalho. Como o câmbio posteriormente passou a apresentar apreciação lenta e gradual, isso provocou efeito inverso, como se vê na tabela. 
de da relação entre aluguel e preço do imóvel, que pode apresentar grandes flutuações no curto prazo.

\subsection{Os que possuem riqueza imobiliária}

É certo que a distribuição de riqueza entre famílias está associada ao ciclo de vida da família. Em outras palavras, por razões ligadas ao ciclo produtivo dos indivíduos, famílias mais velhas têm maior acúmulo de riqueza do que as famílias jovens. A Tabela 11 apresenta dados referentes à propriedade de riqueza imobiliária, segundo atributos da família e da pessoa de referência.

TABELA 11- RIQUEZA IMOBILIÁRIA FAMILIAR, SEGUNDO DIVERSOS ATRIBUTOS

\begin{tabular}{llcc}
\hline \multirow{2}{*}{ Atributos } & Categorias & \multicolumn{2}{c}{ Riqueza Imobiliária } \\
\cline { 2 - 4 } Faixa de Idade da pessoa de referência & Até 19 anos & $56,40 \%$ & $43,60 \%$ \\
& De 20 a 29 anos & $52,20 \%$ & $47,80 \%$ \\
& De 30 a 39 anos & $32,95 \%$ & $67,05 \%$ \\
& De 40 a 49 anos & $22,60 \%$ & $77,40 \%$ \\
& De 50 a 59 anos & $16,80 \%$ & $83,20 \%$ \\
& De 60 a 64 anos & $13,90 \%$ & $86,10 \%$ \\
& Com 65 anos e mais & $14,10 \%$ & $85,90 \%$ \\
Pessoa de referência - Aposentado & Aposentado & $13,10 \%$ & $86,90 \%$ \\
& Não aposentado & $29,00 \%$ & $71,00 \%$ \\
Pessoa de referência - Pensionista & Pensionista & $17,60 \%$ & $82,40 \%$ \\
& Não Pensionista & $26,60 \%$ & $73,40 \%$ \\
Rendimento mensal da família & Até 5 sm & 28,74 & 71,26 \\
& 5 - 10 sm & 22,55 & 77,45 \\
Pessoa de referência - Anos completos de & 10 sm ou + & 17,05 & 82,95 \\
estudo & Sem instrução & $19,70 \%$ & $80,30 \%$ \\
& 1 a 3 anos & $21,60 \%$ & $78,40 \%$ \\
& 4 a 7 anos & $26,30 \%$ & $73,70 \%$ \\
& 8 a 10 anos & $31,10 \%$ & $68,90 \%$ \\
& 11 a 14 anos & $29,40 \%$ & $70,60 \%$ \\
& 15 anos ou mais & $22,30 \%$ & $77,70 \%$ \\
\hline
\end{tabular}

Como se constata facilmente, enquanto mais da metade das pessoas de referência com até 19 anos não possui riqueza imobiliária, esse percentual cai para $22 \%$ entre os que estão entre 40 e 49 anos e para apenas $14 \%$ entre os que têm 65 anos ou mais. Observe ainda que ser aposentado ou pensionista significa ter maiores chances de possuir riqueza imobiliária. Aqui também está presente o efeito idade. Também, como se pode observar, possuir ou não imóvel está associado 
ao nível de renda familiar, mas não ao grau de escolaridade da pessoa de referência do domicílio. Nesse caso, quanto mais elevada a escolaridade da pessoa de referência, menor a incidência de riqueza imobiliária.

TABELA 12- RIQUEZA IMOBILIÁRIA FAMILIAR, SEGUNDO TIPO DE FAMÍLIA

\begin{tabular}{lcc}
\hline & \multicolumn{2}{c}{ Riqueza Imobiliária } \\
\cline { 2 - 3 } Tipo de família & Não possui & Possui \\
\hline \hline Mãe com todos os filhos menores de 14 anos & 43,54 & 56,46 \\
Casal com todos os filhos menores de 14 anos & 33,74 & 66,26 \\
Outros tipos de família & 31,54 & 68,46 \\
Mãe com fillhos menores de 14 e de 14 anos ou mais & 28,94 & 71,06 \\
Casal sem fillhos & 24,88 & 75,12 \\
Casal com filhos menores de 14 e de 14 anos ou mais & 20,02 & 79,98 \\
Mãe com todos os filhos de 14 anos ou mais & 18,75 & 81,25 \\
Casal com todos os filhos de 14 anos ou mais & 13,16 & 86,84 \\
\hline \hline
\end{tabular}

Os dados apresentados na Tabela 12 mostram a incidência de riqueza segundo o tipo de estruturação familiar. Casais com filhos já maiores de 14 anos constituem o tipo de família com maior incidência relativa de riqueza imobiliária. Por outro lado, famílias compostas apenas por mães (ausência do pai) e com todos os filhos menores de 14 anos, assim como o casal com todos os filhos menores de 14 anos, apresentam os menores índices de propriedade de riqueza imobiliária, ratificando a importância do efeito idade na propriedade de riqueza imobiliária. $\mathrm{O}$ papel preponderante do efeito idade (ou ciclo de vida) pode ainda ser corroborado pelo fato de que a segunda maior incidência de riqueza imobiliária, segundo tipo de família, é de famílias "chefiadas" por mães e com filhos com idade superior a 14 anos.

\subsection{A distribuição do estoque de capital em residência}

De forma semelhante à apresentada por Reis et al. (2001), pouco mais de 26\% das famílias não detinham a propriedade do imóvel em que moravam em 2004, confirmando a tendência de redução desse percentual em toda a década de 1990. Também em consonância com outra tendência observada, a participação no total de riqueza imobiliária detida pelo decil mais rico, reduziu-se para 41,8\% em 2004, frente a 49\% em 1999. A Tabela 13 apresenta a distribuição de riqueza em decis, apresentando os resultados em valores absolutos e relativos.

Observe que os dois primeiros decis (D3 e D4) detinham em conjunto $\mathrm{R} \$$ 19,38 bilhões em 1995 e passaram a R $\$$ 72,52 bilhões em 2004, o que representa um crescimento de $274 \%$, equivalente a uma valorização média anual de $15 \%$ em termos nominais. Utilizando-se o deflator implícito do PIB, veri- 
fica-se que o ganho real foi de $66,5 \%$, o que equivale a uma valorização real anual média de $5,83 \%$. Essa elevação do valor do estoque de riqueza entre os mais pobres decorre de dois efeitos: em primeiro lugar há crescimento expressivo do número de proprietários de imóveis baratos, a confirmar tendência já observada por Reis et al. (2001); em segundo lugar, pelo fato de que o parâmetro $\alpha$ eleva-se para os imóveis mais simples quando a economia se estabiliza.

TABELA 13- DISTRIBUIÇÃO ABSOLUTA E PERCENTUAL (SIMPLES E ACUMULADA) DO VALOR DO ESTOQUE DE IMÓVEIS

\begin{tabular}{|c|c|c|c|c|c|c|c|c|c|}
\hline \multirow[b]{2}{*}{ Decis } & \multicolumn{3}{|c|}{1995} & \multicolumn{3}{|c|}{1999} & \multicolumn{3}{|c|}{2004} \\
\hline & R\$ (bi) & $F_{i}$ & $F_{a c}$ & RS (bi) & $F_{i}$ & $F_{a c}$ & RS (bi) & $F_{i}$ & $F_{a c}$ \\
\hline Até D2 & - & - & - & - & - & - & - & - & - \\
\hline D3 & 1,82 & 0,00150 & 0,002 & 5,69 & 0,00488 & 0,005 & 3,85 & 0,00249 & 0,002 \\
\hline D4 & 17,56 & 0,01451 & 0,016 & 25,97 & 0,02226 & 0,027 & 68,67 & 0,04448 & 0,047 \\
\hline D5 & 38,87 & 0,03211 & 0,048 & 47,96 & 0,04110 & 0,068 & 99,70 & 0,06458 & 0,112 \\
\hline D6 & 65,40 & 0,05403 & 0,102 & 73,08 & 0,06263 & 0,131 & 125,37 & 0,08122 & 0,193 \\
\hline D7 & 96,05 & 0,07935 & 0,181 & 101,95 & 0,08737 & 0,218 & 152,93 & 0,09907 & 0,292 \\
\hline D8 & 137,65 & 0,11372 & 0,295 & 140,37 & 0,12030 & 0,339 & 188,91 & 0,12237 & 0,414 \\
\hline D9 & 212,92 & 0,17590 & 0,471 & 204,50 & 0,17526 & 0,514 & 252,61 & 0,16364 & 0,578 \\
\hline D10 & 640,20 & 0,52889 & 1,000 & 567,34 & 0,48621 & 1,000 & 651,65 & 0,42214 & 1,000 \\
\hline
\end{tabular}

Os dados de 1995 e 1999 estão em Reis et al. (2001). Para o ano de 2004, calculado pelos autores.

No extremo oposto, os $20 \%$ que mais detêm estoque de riqueza imobiliária, apesar de apresentar ligeiro crescimento em termos nominais (passa de $\mathrm{R} \$$ 853,12 bilhões em 1995 para $\mathrm{R} \$$ 904,26 em 2004, com crescimento nominal de apenas 6\%) têm redução expressiva no estoque de riqueza imobiliária que detêm; em termos reais, apresenta redução superior a 50\% no valor de seus ativos em riqueza imobiliária. Esse comportamento também se verifica no último decil de riqueza imobiliária: enquanto esse grupo detinha $53 \%$ da riqueza imobiliária do País em 1999, em 2004 esse percentual cai para 42,2\%. $\mathrm{O}$ resultado que pode ser denominado de transição de ativos corrobora o padrão internacional de portfólio de ativos do segmento mais rico da sociedade, que preserva maior parcela de seus ativos em riqueza financeira. No caso brasileiro isso tende até a ser mais expressivo, tendo em vista os maiores retornos do setor financeiro e o menor grau de incerteza na economia.

A resultante é que o grau de concentração de riqueza imobiliária medido pelo coeficiente de Gini apresenta persistente redução desde 1995. Como apresentado no Gráfico 1, o Gini passa de o,6999 para 0,6612 em 1999 e atinge o valor de 0,5529 em 2004. A redução de 14,7 pontos no coeficiente em apenas 10 anos reflete não apenas o processo de estabilização da economia, como também a transição de ativos dos segmentos mais abastados da 
sociedade que deslocou parte de seus ativos de imóveis para aplicações financeiras.

A distribuição conjunta de renda e riqueza imobiliária, tal como apresentada na Tabela 14 e pelo Gráfico 2, revela lentamente que os segmentos de menor renda estão tendo acesso à riqueza imobiliária, fazendo com que progressivamente o grau de concentração se reduza. Enquanto em 1995 o segmento de menor renda, representado pelos dois primeiros decis, detinha apenas 7,04\% da riqueza imobiliária, passando a deter 9,37\% em 2004. O segmento de renda média, aqui representado pelos decis 4, 5 e 6 que detinham 17,25\% da riqueza imobiliária em 1990, passa a deter 21,09\% em 2004.

GRAFICO 1- DISTRIBUIÇÃO DA RIQUEZA IMOBILIARIA E COEFICIENTE DE GINI

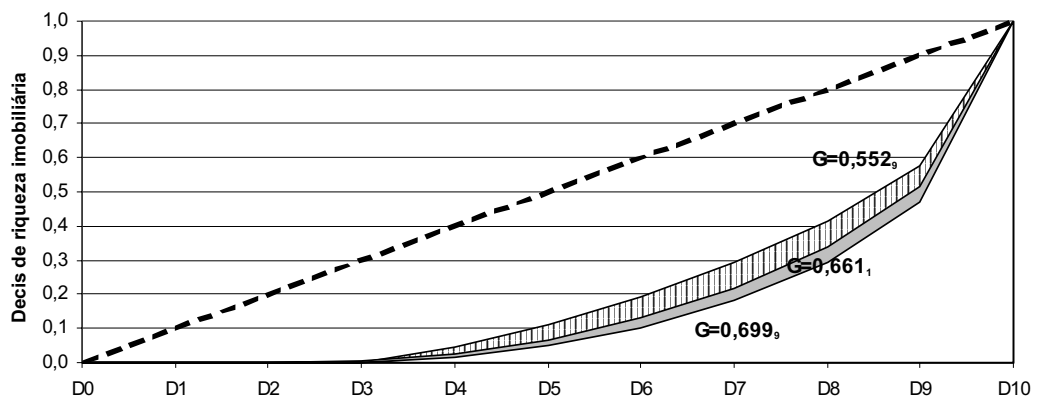

$\square 2004 \square 1999 \square 1995$

Também no extremo superior de renda, representado pelos decis 9 e 10, verifica-se que sua participação na riqueza imobiliária declinou de 51,78\% em 1995, para 42,56\% em 2004, corroborando mais uma vez a hipótese de diversificação de portfólio dos segmentos mais abastados da sociedade. A resultante desse processo pode ser expressa pelo índice de Gini da riqueza imobiliária segundo classes de rendimento: passou de 0,4303 para 0,3256, com redução de 10,5 pontos percentuais. 
Tabela 14- Distribuição do valor do estoque em decis de renda

\begin{tabular}{ccccccc}
\hline \multirow{2}{*}{$\begin{array}{c}\text { Decis de } \\
\text { renda }\end{array}$} & \multicolumn{2}{c}{$\mathbf{1 9 9 5}$} & \multicolumn{2}{c}{$\mathbf{1 9 9 9}$} & \multicolumn{2}{c}{$\mathbf{2 0 0 4}$} \\
\cline { 2 - 7 } & $\mathbf{( \% )}$ & $\mathbf{( \% \mathbf { a c } )}$ & $\mathbf{( \% )}$ & $\mathbf{( \% \mathbf { a c } )}$ & $\mathbf{( \% )}$ & $\mathbf{( \% \mathbf { a c } )}$ \\
\hline \hline D1 & 0,0316 & 0,0316 & 0,0379 & 0,0379 & 0,0422 & 0,0422 \\
D2 & 0,0388 & 0,0704 & 0,0428 & 0,0807 & 0,0515 & 0,0937 \\
D3 & 0,0401 & 0,1105 & 0,0421 & 0,1228 & 0,0554 & 0,1491 \\
D4 & 0,0424 & 0,1529 & 0,0509 & 0,1737 & 0,0617 & 0,2108 \\
D5 & 0,0538 & 0,2067 & 0,0571 & 0,2308 & 0,0737 & 0,2845 \\
D6 & 0,0763 & 0,2830 & 0,0753 & 0,3061 & 0,0755 & 0,3600 \\
D7 & 0,0885 & 0,3715 & 0,0876 & 0,3937 & 0,0907 & 0,4507 \\
D8 & 0,1107 & 0,4822 & 0,1108 & 0,5045 & 0,1237 & 0,5744 \\
D9 & 0,1574 & 0,6396 & 0,1475 & 0,6520 & 0,1323 & 0,7067 \\
D10 & 0,3604 & 1,0000 & 0,3480 & 1,0000 & 0,2933 & 1,0000 \\
\hline \hline
\end{tabular}

Os dados para 1995 e 1999, estão em Reis et al. (2001). Para 2004, calculado pelos autores.

GRAFICO 2- DISTRIBUIÇÃO DA RIQUEZA IMOBILIÁRIA, SEGUNDO DECIS DE RENDA

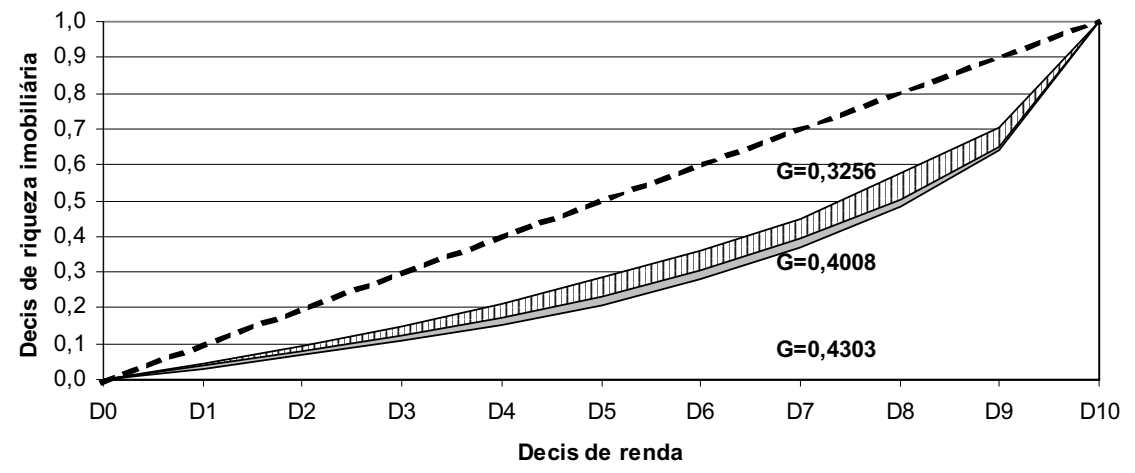

ए2004 $\square 1999 \square \square 1995$

O efeito aqui identificado de melhora na distribuição de riqueza imobiliária pode, em realidade, ser decorrência da hipótese aqui assumida de estabilidade do valor de $\alpha$ para todos os tipos de imóveis. É razoável admitir que com o progressivo ajuste da economia brasileira - redução das taxas de inflação e de absorção dos choques externos vividos na segun- 
da metade da década de 1990 - tenha havido uma elevação do valor de $\alpha$ para os imóveis mais populares enquanto que, para os imóveis mais valiosos, este permaneceu constante, podendo mesmo ter-se reduzido ${ }^{26}$.

Uma vez vistos esses resultados, pode-se perguntar: afinal, a concentração imobiliária é particularmente elevada? Ou dito de outra forma, o fato de quase 30\% das famílias não ter imóvel próprio é sinônimo de exclusão social? Poderíamos começar a responder essas questões colocando os termos de forma ligeiramente diferente: será que todos os que não têm imóvel não o têm por impossibilidade de renda ou de acesso a crédito, ou será que parte desse conjunto não tem imóvel simplesmente por opção. A escolha entre ter ou não imóvel está associada a variáveis macroeconômicas como crescimento do PIB, mercado de trabalho, taxa de juros, oferta de crédito imobiliário e a condições e preferências individuais como renda e escolaridade média da família, aversão ao risco, preferência por liquidez, etc. Sendo assim, a distribuição de riqueza e as medidas de desigualdade a ela associadas, como o coeficiente de Gini, podem estar viesadas, caso a parcela de famílias que poderiam ter imóveis deixem de tê-los por razões estritamente ligadas à preferência e não à limitação de renda. Considerar como "desprovidos" de riqueza imobiliária aqueles que tendo a possibilidade de tê-la optam por não tê-la - seja substituindo por outras formas de riqueza ou simplesmente aumentando seu consumo - induz a uma superestimação da desigualdade de propriedade de ativos imobiliários ${ }^{27}$.

\subsection{Os que não têm, mas poderiam ter riqueza imobiliária}

Como vimos na primeira seção, aproximadamente $17,4 \%$ do total de imóveis urbanos em 1995 eram alugados, totalizando 5.440.387 imóveis. Em 2004, esse número era 7.816 .470 , perfazendo algo próximo a $18 \%$ dos imóveis urbanos ${ }^{28}$. Destes, 3,2\% em 1995 e 2,8\% em 2004 pagavam aluguel, mas também recebiam aluguel, tendo, portanto, alguma riqueza imobiliária.

26 Parece-nos plausível admitir a hipótese de que, em períodos inflacionários, os imóveis mais valorizados tenham um valor de $\alpha$ mais próximo da unidade percentual, enquanto os imóveis populares estejam mais próximos de 0,005 . Isso decorreria do fato de que imóveis mais valorizados são normalmente administrados por empresas que conseguem preservar a renda de aluguel, não ocorrendo o mesmo com os detentores de imóveis mais populares. Além disso, o público usuário dos dois tipos de imóveis é assimétrico em relação aos efeitos da inflação sobre suas rendas. Logo, é plausível admitir que, com a queda da inflação, o valor de $\alpha$ se eleve para os imóveis populares, mantendo-se estável ou mesmo se reduzindo para os imóveis mais valorizados. Também nesse caso, os efeitos da queda da inflação sobre a renda dos usuários são assimétricos, porém em sentido inverso.

27 No presente artigo, não é nosso objetivo discutir políticas de acesso à casa própria. Mas devemos chamar a atenção para o fato de que medidas equivocadas de "exclusão" e desigualdade de riqueza imobiliária podem levar a desenhos equivocados de programas voltados ao acesso à casa própria.

28 A divergência do total de imóveis alugados é explicada pelo fato de que do total de imóveis alugados, nem todos têm valor de aluguel declarado. Assim, em 1995, do total de 5.570.281 imóveis alugados, 5.455.708 declararam o valor de aluguel efetivamente pago. 
Pagar aluguel e não receber aluguel poderia sugerir um grupo homogêneo de indivíduos que estão alijados de qualquer possibilidade de acumulação de riqueza. Mas, ao analisarmos esse conjunto, observamos que há enorme desigualdade entre seus membros (por exemplo, desvio-padrão da renda dentre os que não possuem imóvel era $\mathrm{R} \$ \mathbf{1 . 1 5 7 , 5 4}$ em 1995 e $\mathrm{R} \$ 2.173,36$, em 2004). Além disso, a dispersão observada entre os valores de aluguel que são pagos também indica essa heterogeneidade. Como visto na seção 2.3, os valores médios de aluguel eram $\mathrm{R} \$ 186,46$ e $\mathrm{R} \$ 239,14$, respectivamente em 1995 e 2004, sendo R $\$ 192,33$ e 207,50 os valores dos respectivos desviospadrão.

Como se pode observar na Tabela 15, os valores de aluguel no País são particularmente reduzidos. Mais de $45 \%$ dos aluguéis pagos em 1995 eram inferiores a $\mathrm{R} \$ 100,00$ mensais e praticamente um quarto dos imóveis em 2004 estava nesse limite de valor. De forma similar, aproximadamente quatro de cada cinco imóveis alugados, tanto em 1995 quanto em 2004, tinham valor de aluguel não superior a $R \$ 300,00$. No outro extremo, verifica-se que menos de $1 \%$ dos imóveis alugados no País têm aluguel mensal superior a $\mathrm{R} \$$ 1.000,00. Observe ainda que enquanto na primeira classe de aluguel (até $\mathrm{R} \$$ $100,00)$ estão praticamente $40 \%$ e $23 \%$ dos imóveis alugados, respectivamente em 1995 e 2004, estes representam apenas $16 \%$ e $7 \%$ do total de aluguéis pagos para os mesmos anos. Por outro lado, no extremo oposto, na última classe (valores superiores a $\mathrm{R} \$ 1.000,00$ ) de valores estão menos de apenas $1 \%$ dos imóveis alugados, mas estes respondem por $5 \%$ do total de aluguéis pagos. Se tomarmos as duas primeiras classes e as duas últimas, verificaremos que o aluguel médio dos últimos é aproximadamente 9 vezes (9,2 em 1995 e 8,1 em 2004) superior ao dos primeiros. E essa razão, quando tomamos apenas os dois extremos da distribuição chega a quase 20 vezes.

Ainda na Tabela 15, apresenta-se, para as mesmas classes de aluguel, a razão entre o dispêndio com aluguel e a renda familiar. Observe que essa razão, exceção feita à primeira classe de aluguel, é praticamente estável (passa de $20 \%$ para aluguéis até $R \$ 200$ para $22 \%$ para aluguéis superiores a $R$ \$ 1.000 em 1995 e fica estável em torno de 17 a 18\% em 2004). Como nos segmentos de renda mais baixa itens de despesa básica como alimentação, transporte, higiene, dentre outros têm maior relevância na renda familiar, decorre que o segmento de renda mais alta que não possui riqueza imobiliária, apesar de pagar aluguéis mais elevados, compromete parcela declinante de sua renda com despesa de moradia ${ }^{29}$.

\footnotetext{
${ }^{29}$ Feito o mesmo cálculo para a distribuição de decis de renda, como apresentado nas tabelas A2 e A3 do anexo, observa-se uma tendência fortemente declinante da participação do aluguel na renda familiar, tanto em 1995 quanto em 2004. No primeiro caso, enquanto o aluguel representa em média $67 \%$ da renda familiar para o primeiro decil de renda, esse percentual cai para apenas $13 \%$ no último decil. Para 2004 essas percentagens são, respectivamente, $54 \%$ e $10 \%$.
} 
TABELA 15- DISTRIBUIÇÃO DOS DOMICÍLIOS ALUGADOS E DO TOTAL PAGO DE ALUGUEL, SEGUNDO CLASSES DE ALUGUEL E RAZÃO RENDA/ALUGUEL - BRASIL - 1995-2004

\begin{tabular}{lcccccc}
\hline \multirow{2}{*}{ Classes de Aluguel pago } & \multicolumn{3}{c}{$\mathbf{1 9 9 5}$} & \multicolumn{3}{c}{$\mathbf{2 0 0 4}$} \\
& Imóveis & Aluguel & (Aluguel/Y) & Imóveis & Aluguel & (Aluguel/Y) \\
\hline até R\$ 100,00 & $46,73 \%$ & $16,13 \%$ & 0,125 & $22,86 \%$ & $7,10 \%$ & 0,132 \\
de R\$ 101 a R\$ 200 & $25,02 \%$ & $21,40 \%$ & 0,201 & $34,70 \%$ & $23,50 \%$ & 0,180 \\
de R\$ 201 a R\$ 300 & $12,43 \%$ & $17,82 \%$ & 0,211 & $21,11 \%$ & $23,13 \%$ & 0,176 \\
de R\$ 301 a R\$ 400 & $6,89 \%$ & $13,64 \%$ & 0,222 & $9,77 \%$ & $14,88 \%$ & 0,161 \\
de R\$ 401 a R\$ 500 & $3,79 \%$ & $9,67 \%$ & 0,204 & $4,93 \%$ & $9,68 \%$ & 0,154 \\
de R\$ 501 a R\$ 600 & $2,06 \%$ & $6,37 \%$ & 0,246 & $2,67 \%$ & $6,37 \%$ & 0,148 \\
de R\$ 601 a R\$ 1.000 & $2,52 \%$ & $10,51 \%$ & 0,221 & $3,18 \%$ & $10,37 \%$ & 0,155 \\
mais de R\$ 1.000 & $0,56 \%$ & $4,46 \%$ & 0,223 & $0,77 \%$ & $4,96 \%$ & 0,171 \\
\hline Valor médio do aluguel & \multicolumn{3}{c}{$\mathrm{R} \$ 186,46$} \\
Desvio-padrão & $\mathrm{R} \$ 192,33$ & $\mathrm{R} \$ 239,14$ & $\mathrm{R} \$ 207,50$ \\
\hline
\end{tabular}

Na Tabela 16, observa-se a distribuição do valor de aluguel em decis, segundo decis de renda do chefe do domicílio, somente para o grupo de indivíduos que paga aluguel e não têm riqueza imobiliária. Como se pode observar, o primeiro decil de renda em 1995, respondia por menos de $4 \%$ do total de aluguéis pagos, enquanto o último decil de renda respondia por $26 \%$ do total de aluguéis pagos naquele ano. Em 2004, esses percentuais correspondem a 4,6\% para o primeiro decil e 20,9\% para o último, o que indica que não houve alterações substantivas no período, apesar da redução do peso relativo do último decil.

Feitas essas considerações, podemos agora considerar a pergunta: será que os dois grupos extremos apresentados na Tabela 16 estão igualmente alijados do acesso à riqueza imobiliária? Será que aqueles que ganham muito pouco e pagam aluguéis de até 100 reais estão tão limitados em termos de acesso à riqueza imobiliária quanto os que ganham muito e pagam aluguéis de mais de mil reais (ainda que isso represente pequena parcela de sua renda)? É evidente que não. No segundo grupo - o de renda elevada - a ausência de riqueza imobiliária parece decorrer de preferências familiares e não de limitação de renda ou de acesso a crédito. Mas se isso é valido para o caso extremo, não o seria para classes de renda que lhe são próximas? Devemos tomar somente os extremos ou será possível utilizar as classes vizinhas? 
TABELA 16- DISTRIBUIÇÃO DO VALOR DE ALUGUEL DOS QUE NÃO TÊM RIQUEZA IMOBILIÁRIA, SEGUNDO DECIS DE RENDA - BRASIL - 1995-2004

\begin{tabular}{|c|c|c|c|c|}
\hline \multirow{3}{*}{$\begin{array}{c}\text { Decis de } \\
\text { renda }\end{array}$} & \multicolumn{4}{|c|}{ Valor do aluguel } \\
\hline & \multicolumn{2}{|c|}{1995} & \multicolumn{2}{|c|}{2004} \\
\hline & $(\%)$ & $(\%$ ac $)$ & $(\%)$ & $(\%$ ac $)$ \\
\hline D1 & $3,7 \%$ & $3,7 \%$ & $4,64 \%$ & $4,64 \%$ \\
\hline D2 & $3,8 \%$ & $7,6 \%$ & $5,39 \%$ & $10,03 \%$ \\
\hline D3 & $5,2 \%$ & $12,8 \%$ & $6,69 \%$ & $16,72 \%$ \\
\hline D4 & $6,4 \%$ & $19,2 \%$ & $7,87 \%$ & $24,58 \%$ \\
\hline D5 & $7,2 \%$ & $26,4 \%$ & $7,49 \%$ & $32,07 \%$ \\
\hline D6 & $8,6 \%$ & $34,9 \%$ & $9,08 \%$ & $41,15 \%$ \\
\hline D7 & $10,4 \%$ & $45,3 \%$ & $10,97 \%$ & $52,12 \%$ \\
\hline D8 & $13,8 \%$ & $59,2 \%$ & $11,46 \%$ & $63,58 \%$ \\
\hline D9 & $14,8 \%$ & $73,9 \%$ & $15,50 \%$ & $79,07 \%$ \\
\hline D10 & $26,1 \%$ & $100,0 \%$ & $20,93 \%$ & $100,00 \%$ \\
\hline
\end{tabular}

Ampliando-se a faixa e tomando-se os dois últimos decis de renda, o montante de aluguel pago correspondia a $41 \%$ do total de aluguéis pagos em 1995, portanto, mais do dobro de sua incidência relativa. Por outro lado, os dois primeiros decis de renda pagavam o equivalente a 7,6\% do total de aluguéis pagos no País, algo próximo a 40\% de sua incidência relativa. Observe ainda que a distribuição pouco se alterou entre 1995 e 2004. Enquanto os dois primeiros decis eram responsáveis por 7,6\% do total de aluguéis pagos no primeiro desses anos, passam para $10 \%$ no segundo. Por outro lado, os dois últimos decis que respondiam por 41\% dos aluguéis pagos em 1995 têm sua participação reduzida para 36\% em 2004. Em síntese, observa-se um achatamento da distribuição, ainda que a estrutura não tenha se alterado entre 1995 e 2004.

\subsection{O novo cálculo da distribuição da riqueza e da desigualdade de riqueza imobiliária}

Tomando-se os dois últimos decis de renda dentre os que pagam aluguel, estamos tratando de algo em torno de $39 \%$ dos aluguéis pagos no País, tanto em 1995 como em 2004 (ver Tabela 16). Observe que o valor de aluguel correspondente ao oitavo decil de renda é aproximadamente $\mathrm{R} \$ 380,00$ em 1995 e R \$ 450,00 em 2004. Esses valores correspondem aproximadamente a 1,0 desvio-padrão à direita da média de cada ano, cobrindo em média não mais do que $11 \%$ desse grupo de imóveis alugados, mas respondendo por praticamente $34 \%$ do aluguel pago no País. O grupo de indivíduos aqui desta- 
cado distingue-se do restante não apenas por pagar um valor de aluguel muito superior à média, como também por apresentar renda mensal equivalente à do penúltimo decil da distribuição de riqueza, ou seja, composto por proprietários que têm $20 \%$ da riqueza imobiliária do País ${ }^{30}$.

Podemos agora recalcular a distribuição de riqueza imobiliária, desconsiderando esse grupo de indivíduos que não têm imóvel, mas poderiam ter, se assim quisessem. Como esse conjunto encontra-se nos três primeiros decis da distribuição original (os decis daqueles que não têm imóvel), excluí-los, significa reduzir a desigualdade de ativos imobiliários. A Tabela 17 e o Gráfico 3 apresentam essa nova distribuição, que passaremos a chamar de distribuição ajustada, para 1995, 1999 e 2004.

TABELA 17- DISTRIBUIÇÃO PERCENTUAL (SIMPLES E ACUMULADA) DA RIQUEZA IMOBILIÁRIA

\begin{tabular}{ccccccc}
\hline \multirow{2}{*}{ Decis } & \multicolumn{2}{c}{$\mathbf{1 9 9 5}$} & \multicolumn{2}{c}{$\mathbf{1 9 9 9}$} & \multicolumn{2}{c}{$\mathbf{2 0 0 4}$} \\
\cline { 2 - 7 } & $\mathbf{( \% )}$ & $\mathbf{( \% \mathbf { a c } )}$ & $\mathbf{( \% )}$ & $\mathbf{( \% \mathbf { a c } )}$ & $\mathbf{( \% )}$ & $\mathbf{( \% \mathbf { a c } )}$ \\
\hline \hline D1 & 0,0000 & 0,0000 & 0,0000 & 0,0000 & 0,0000 & 0,0000 \\
D2 & 0,0000 & 0,0000 & 0,0265 & 0,0265 & 0,0540 & 0,0540 \\
D3 & 0,0366 & 0,0366 & 0,0438 & 0,0703 & 0,0545 & 0,1085 \\
D4 & 0,0567 & 0,0933 & 0,0696 & 0,1399 & 0,0854 & 0,1939 \\
D5 & 0,0885 & 0,1818 & 0,0845 & 0,2244 & 0,0898 & 0,2837 \\
D6 & 0,1045 & 0,2863 & 0,0975 & 0,3219 & 0,0937 & 0,3774 \\
D7 & 0,1179 & 0,4042 & 0,1081 & 0,4300 & 0,1082 & 0,4856 \\
D8 & 0,1203 & 0,5245 & 0,1254 & 0,5554 & 0,1141 & 0,5997 \\
D9 & 0,1533 & 0,6778 & 0,1422 & 0,6976 & 0,1371 & 0,7368 \\
D10 & 0,3222 & 1,0000 & 0,3024 & 1,0000 & 0,2632 & 1,0000 \\
\hline
\end{tabular}

GRAFICO 3- DISTRIBUIÇÃO DA RIQUEZA IMOBILIÁRIA AJUSTADA E COEFICIENTE DE GINI

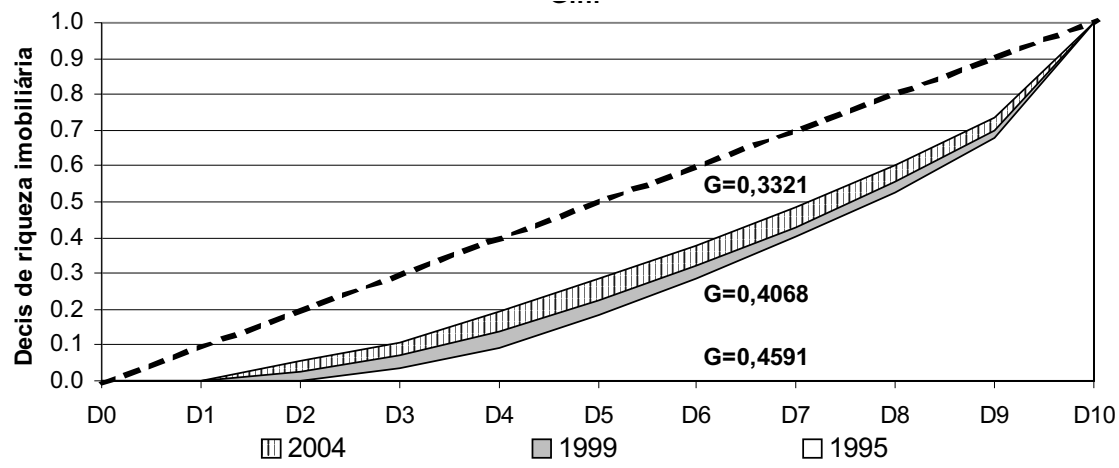

30 A renda média deste grupo é de $\mathrm{R} \$ 4.211,28$ (2004) e para o grupo que detém $20 \%$ da riqueza imobiliária a renda média é de $\mathrm{R} \$ 3.405,43$ (2004). 
É importante destacar que a correção proposta melhora significativamente a distribuição de riqueza. Observe que enquanto na distribuição original praticamente $30 \%$ dos chefes de domicílio não tinham riqueza imobiliária, feita a correção esse percentual cai para 25\% em 1995, 18\% em 1999 e 14\% em 2004. Além disso, pela redução do número de indivíduos que não têm propriedade imobiliária, há mudança na distribuição dos que têm, fazendo com que a desigualdade seja expressivamente reduzida. Comparando-se os resultados do coeficiente de Gini, observa-se redução de aproximadamente 24 pontos percentuais para os três anos apresentados.

Outro aspecto importante, é que o número de indivíduos sem qualquer riqueza imobiliária é reduzido em aproximadamente 10 pontos percentuais. Visto sem o ajustamento aqui proposto, o número de famílias sujeitas a risco de desabrigo estava situado em torno de 7,5 milhões (o que equivale a aproximadamente 33,7 milhões de pessoas). No entanto, quando desse conjunto desconsideramos aquelas que por suas características poderiam ter riqueza imobiliária e, conseqüentemente, não estariam sujeitas a risco de desabrigo, esse contingente cai para 5,1 milhões de famílias (o que equivale a aproximadamente 22,4 milhões de pessoas). Isso equivale a reduzir mais de 2 milhões de famílias que sem ter imóveis teriam condições de tê-lo, caso fosse sua preferência.

O mais relevante aqui, entretanto, não é o número em si, mas o que ele pode significar em termos de políticas públicas voltadas à habitação, especialmente à habitação popular. De fato, esse pequeno refinamento importa, sobretudo, para o estudo de segmentos sociais sujeitos a risco de desabrigo e para a formulação de políticas públicas mais ajustadas ao objetivo de reduzir esse risco, focalizando esforços e recursos de modo a ampliar o acesso dos mais desprotegidos à riqueza imobiliária.

\section{Conclusões}

O objetivo deste estudo foi analisar a distribuição do estoque de riqueza em imóveis residenciais no Brasil para os anos de 1995 e 2004, procurando enfatizar as transformações dessa distribuição durante esse período, reforçando tendência já identificada ao longo da década de 1990, conforme indicado por Reis et al. (2001), que indicava redução da desigualdade na propriedade de riqueza imobiliária.

Para se obter uma estimativa da distribuição de riqueza imobiliária, utilizouse um modelo de estimação do valor de aluguel segundo atributos dos imóveis, da infra-estrutura associada ao imóvel e de sua vizinhança e localização. Por meio da utilização das estimativas obtidas, imputou-se para todos os imóveis próprios, um hipotético valor de aluguel, de acordo com seus 
atributos físicos, de infra-estrutura e de vizinhança e localização. Em seguida, assumindo-se a hipótese de estabilidade da relação entre valor de aluguel e preço do imóvel, obteve-se o valor do imóvel para todos os imóveis próprios e alugados do País. A partir daí, para todos quantos tinham seu próprio imóvel (pago ou ainda em fase de pagamento) e/ou recebiam renda de aluguel, atribuiu-se o valor do estoque de riqueza correspondente. Deve-se observar que, no caso de aluguéis recebidos, a estimativa de riqueza foi feita aplicando-se sobre a informação de aluguel recebido a relação aluguel/preço do imóvel, que se supôs constante. Dessa forma, obteve-se para cada um dos três anos analisados (1995, 1999 e 2004) um vetor de valores da riqueza imobiliária, correspondente aos domicílios que tinham imóvel e/ou recebiam renda de aluguel.

Sobre esses vetores de riqueza imobiliária, foram feitos estudos sobre sua distribuição para os três anos. Os resultados obtidos indicam que o perfil da distribuição do valor do estoque de residências sofreu alterações no período, ratificando a tendência já observada de redução da desigualdade. E esse resultado deve-se a dois fenômenos: aumento do número de proprietários e redução da concentração de ativos imobiliários nas mãos dos segmentos mais abastados da sociedade que, segundo nossa hipótese, migraram ativos imobiliários para financeiros, como resultado da estabilização da economia e dos ganhos elevados propiciados por juros elevados.

No estudo da distribuição de riqueza imobiliária, sugerimos que parte da concentração observada (expressa aqui pelo coeficiente de Gini) estava incorretamente medida, posto que do grupo que não possui riqueza imobiliária há uma parcela não desprezível que tendo todas as condições para ter riqueza imobiliária não a tem, levando-nos a concluir que se trata de preferência por realização de poupança financeira ou simplesmente ampliação do consumo. Mostramos ainda que esse conjunto de indivíduos se aproxima do grupo que detém parcela expressiva da riqueza imobiliária do País.

Como forma alternativa de estudo da desigualdade de ativos imobiliários, retiramos do conjunto de "despossuídos" esse subconjunto de indivíduos e refizemos os cálculos de desigualdade e do conjunto de indivíduos sem qualquer riqueza imobiliária e com baixa renda. Como mostramos, esse procedimento não apenas reduziu expressivamente o grau de desigualdade de riqueza imobiliária do País, como fez com que o contingente de famílias sem riqueza imobiliária se reduzisse de 7,5 milhões para 5,1 milhões.

Chamamos a atenção do leitor para o fato de que esse procedimento, mais do que apenas um refinamento estatístico, pode e deve ser usado para melhor focalizar e desenhar políticas públicas voltadas para reduzir o risco de desabrigo e para ampliar o acesso à riqueza imobiliária, sobretudo para os segmentos mais desprovidos da sociedade. 
Estudar a distribuição de riqueza imobiliária e o papel que ela tem como elemento que possibilita e induz o acesso à educação das gerações sucessoras - alterando, portanto, não apenas os horizontes de renda que seus sucessores podem obter, como também as possibilidades de crescimento da própria economia ${ }^{31}$ - pode complementar a rica e ampla literatura sobre desigualdade no Brasil ${ }^{32}$ e auxiliar no desenho e na amplitude de políticas voltadas à ampliar o acesso a ativos imobiliários e, indiretamente, à redução da pobreza e da desigualdade no Brasil.

\section{Referências}

ALESINA, A. \& RODRIK, D. (1994). "Distributive politics and economic growth.” The Quarterly Journal of Economics 109:465-489.

AZZONI, C. \& MENEZES-FILHO, N. \& MENEZES, T. \& SILVEIRA NETO, R. (1999). "Regional income convergence among Brazilian States, 19811996: a study using micro-data and pseudo-panel." Anais XXVII Encontro Nacional de Economia, v. II: 1401-18.

BÉNABOU, R. (2000): "Unequal societes: income distribution and the social contract." American Economic Review 90: 96-129.

BENERJEE, A. \& NEWMAN, A. (1993). "Occupational choice and the process of development." Journal of Political Economy 101(2): 274-98.

BOURDIEU, J. \& POSTEL-VINAY, G. \& SUWA-EISENMANN, A. (2002). "Why a rise in wealth ownership did not accompany growth? The puzzle of 'primary' inequality using French data (1800-1940)." URL: http:// www.inra.fr/Internet/Departements/ESR/UR/lea/documents/wp/ wp0207.pdf.

DEININGER, K. \& OLINTO, P. (2000). "Asset distribution, inequality, and growth.” Policy Research Working Paper 2375, The World Bank.

DAVIDSON, R. \& MACKINNON, J. (1993). Estimation and inference in econometrics, Oxford University Press, New York.

FERREIRA, F. H. (2000). "Os determinantes da desigualdade de renda no Brasil: Luta de classes ou heterogeneidade educacional". Texto para Discussão 415, Dep. Economia, PUC-Rio.

FISHLOW A. (1972). "Brazilian size distribution of income." American Economic Association: Papers and Proceedings, 391-402.

GREEN, R. \& HENDERSHOTT, P. (1993). "Demographic factors and real house prices." NBER, Working Paper 4332.

HAUGHWOUT, A. (2000). "Public infrastructure investments, productivity and

31 Ver a respeito Ferreira (2000), Alesina e Rodrik (1994), Persson e Tabellini (1994), Benerjee e Newman (1993), Deininger e Olinto (2000) e Bénabou (2000), Spilerman (2000) entre outros.

32 Fishlow (1972), Langoni (1973), Hoffman (1989), Ramos (1993), Paes de Barros \& Mendonça (1995), Ferreira e Litchfield (1999, 2000), Azzoni (1994, 1999), Ferreira(1995), são exemplos desse debate. 
welfare in fixed geographic areas.” Federal Reserve Bank of New York, proceeds (May).

HOFFMAN, R. (1989): "Evolução da distribuição de renda no Brasil entre pessoas e entre famílias, 1976/86.” In SEDLACEK, G. \& BARROS, R. P. (orgs). Mercado de trabalho e distribuição de renda: uma coletânea. Série Monográfica \#35, IPEA, Rio de Janeiro.

HOLTZ-EAKIN, D. (1994). "Public-sector capital and the productivity puzzle." Review of Economic and Statistics 76:12-44.

KELSTER, L. (2000). "Family structure, race and wealth ownership: a longitudinal exploration of wealth accumulation processes." Working Paper 304, Ohio State University.

LANGONI, C. (1973). Distribuição de renda e desenvolvimento econômico do Brasil. Rio de Janeiro: Expressão e Cultura.

LUCENA, José M. P. (1985). O mercado habitacional no Brasil. FGV-RJ, Série Teses $\mathrm{n}^{\mathrm{o}}$ 9, Rio de Janeiro.

MALPEZZI, S. (1991). "Rent control in developing countries.” BIRD, Discussion Paper 129, Washington.

MELAZZO, E. (1996). “Apontamentos para uma valoração do patrimônio Imobiliário urbano brasileiro.” Anais do IV Encontro da ANPUR: Modernidade, exclusão e a espacialidade do futuro, 504-508, Brasília.

MORAIS, M. (2005). "The housing conditions in Brazilian urban areas during the 1990s.” Texto de Discussão 1085, IPEA, Brasília.

MORANDI, Lucilene (1995). Estoque da riqueza interna tangível e reprodutível Brasil, 1970/95. Dissertação de Mestrado, Universidade Federal Fluminense (UFF), Niterói.

MUNNELL, Alicia (1990). "How does public infrastructure affect regional economic performance?” In MUNNELL, A. (ed.). Is there a shortfall in public capital investment? Boston, MA: Federal Reserve Bank of Boston.

NERI, Marcelo (1999). “Assets, market and poverty in Brazil.” Inter-American Development Bank, Research Network Working Papers Series R-357.

PAES DE BARROS, R. \& MENDONÇA, R. (1996). “Os determinantes da desigualdade no Brasil.” In IPEA. Economia brasileira em perspectiva. Rio de Janeiro: IPEA.

PERSSON, T. \& TABELLINI, G. (1994). "Is inequality harmful for growth? Theory and evidence." American Economic Review 90(3): 600-621.

POTERBA, James (1992). "Taxation and housing: old questions, new answers." NBER WP 3963.

RAMOS, L (1993). A distribuição de rendimentos no Brasil: 1976/85. Rio de Janeiro: IPEA.

SANTOS, C. \& CRUZ, B. (2000): “A dinâmica dos mercados habitacionais metropolitanos: aspectos teóricos e uma aplicação para a Grande São Paulo.” Texto para discussão 713, IPEA, Brasília.

REIS, E. \& TAFNER, P. \& REIFF, L. (2001). "Distribuição de riqueza imobiliária e de renda no Brasil : 1992-1999.” Rio de Janeiro: IPEA (Seminários 
DIMAC no. 75).

SPILERMAN, S. (2000). "Wealth and stratification processes." Annual Review of Sociology 26: 497-524.

ZABEL, Jeffrey (1999). "Controlling for quality in house-price indices.” Journal of Real Estate Finance and Economics, pp. 223-241.

WOLFF, Eduard (2000). "Recent trends in wealth ownership." In SAPRIO, T. \& WOLFF, E. (eds). Benefits and mechanisms for spreading asset ownership in the United States. Nova Iorque: Russel Sage Press.

WOLFF, E. \& D'AMBROSIO, C. (2001). "Is wealth becoming more polarized in the United States?" New York University, mimeo.

Anexo

\section{QUADRO 1. DESCRIÇÃO DAS VARIÁVEIS UTILIZADAS NO MODELO DE ESTIMAÇÃO PARA 2004}

\begin{tabular}{|c|c|c|}
\hline GRUPO & VARIÁVEL-NOME & DESCRIÇÃO DA VARIÁVEL \\
\hline V Dependente & LALUGUEL & Logaritmo do aluguel mensal \\
\hline \multirow{7}{*}{$\begin{array}{l}\text { Tipo de } \\
\text { Moradia }\end{array}$} & APTO & Indica a ocorrência de apartamento (1) ou outro tipo de moradia \\
\hline & PAREDE_AL & $\begin{array}{l}\text { Parede de alvenaria: tijolo, adobe, pedra, concreto em placas ou pré-moldado (recoberto } \\
\text { ou não por reboco), concreto aparente ou taipa revestida, paredes de estrutura de metal e } \\
\text { vidro e as revestidas de mármore, pedra, etc. }\end{array}$ \\
\hline & PAREDE_MA & $\begin{array}{l}\text { Parede de madeira aparelhada: qualquer tipo de madeira aparelhada (independente do } \\
\text { estado de conservação), com exclusão de madeira aproveitada de embalagem, tapume, } \\
\text { etc. }\end{array}$ \\
\hline & PAREDE_TA & $\begin{array}{l}\text { Parede de taipa não revestida: paredes de barro ou cal, areia com estacas e vara de } \\
\text { madeira (tabique, estuque, pau-a-pique, etc.) }\end{array}$ \\
\hline & COB_LAJE & Cobertura de laje de concreto: fundido no local ou pré-fabricada \\
\hline & COB_TBAR & Cobertura de telha de barro: qualquer tipo de telha de barro cozido \\
\hline & COB_ZIN & Cobertura de telha de zinco ou flandres \\
\hline \multirow[b]{2}{*}{$\begin{array}{l}\text { Dimensão do } \\
\text { Imóvel }\end{array}$} & OUTROCOM & Total de cômodos menos dormitórios e banheiros. \\
\hline & DORMITOR & $\begin{array}{l}\text { Número de dormitórios: quartos ou outras dependências que estivessem servindo de } \\
\text { dormitório em caráter permanente. Não foram considerados quartos de vestir ou de } \\
\text { hóspedes. }\end{array}$ \\
\hline \multirow{8}{*}{$\begin{array}{l}\text { Serviços de } \\
\text { Infra-estrutura }\end{array}$} & AGUA_CI & Abastecimento de água com canalização interna. \\
\hline & SANIT_RG & Instalação sanitária - rede geral. \\
\hline & SAN_FSRP & Fossa séptica ligada à rede pluvial. \\
\hline & SAN_FSSE & Fossa séptica sem escoadouro. \\
\hline & SAN_FRUD & Fossa rudimentar. \\
\hline & LIXO_DIR & Lixo coletado diretamente por serviço, empresa pública ou particular. \\
\hline & LIXO_IND & $\begin{array}{l}\text { Lixo coletado indiretamente, quando o lixo fosse depositado em uma caçamba, tanque ou } \\
\text { depósito, fora da residência, para depois ser coletado por serviço, empresa pública ou } \\
\text { particular. }\end{array}$ \\
\hline & ILU_ELET & Iluminação elétrica, com ou sem medidor. \\
\hline \multirow{4}{*}{$\begin{array}{l}\text { Localização e } \\
\text { Municípios }\end{array}$} & LMEDREN & Log da mediana da renda familiar no setor censitário \\
\hline & P_DMOR & Densidade de moradores por cômodo do setor censitário \\
\hline & D_RM & Municípios selecionados na Amostra PNAD como auto-representativos. \\
\hline & D_AUTO & Municípios selecionados na Amostra PNAD como pertencentes à Região Metropolitana \\
\hline
\end{tabular}


TABELA A-1- CLASSES DE RENDA FAMILIAR, ALUGUEL MÉDIO, RENDA MÉDIA E PARTICIPAÇÃO DO ALUGUEL NA RENDA FAMILIAR, SEGUNDO DECIS DE RENDA - BRASIL: 1995

\begin{tabular}{cccccc}
\hline $\begin{array}{c}\text { Decil } \\
\text { Renda }\end{array}$ & $\begin{array}{c}\text { Renda } \\
\text { Domiciliar }\end{array}$ & $\begin{array}{c}\text { A } \\
\text { Aluguel Médio } \\
\text { (em R } \$)\end{array}$ & $\begin{array}{c}\text { Y } \\
\text { Renda Média }\end{array}$ & Y/A & A/Y \\
\hline 1 & Até R\$150 & 64 & 96 & 1,49 & 0,67 \\
2 & $150 \mid-240$ & 70 & 201 & 2,85 & 0,35 \\
3 & $240 \mid-314$ & 96 & 279 & 2,92 & 0,34 \\
4 & $314 \mid-400$ & 114 & 370 & 3,25 & 0,31 \\
5 & $400 \mid-515$ & 130 & 468 & 3,60 & 0,28 \\
6 & $515 \mid-670$ & 153 & 594 & 3,87 & 0,26 \\
7 & $670 \mid-870$ & 185 & 769 & 4,17 & 0,24 \\
8 & $870 \mid-1200$ & 229 & 1.030 & 4,50 & 0,22 \\
9 & $1200 \mid-1905$ & 294 & 1.511 & 5,14 & 0,19 \\
10 & Mais 1905 & 467 & 3.480 & 7,45 & 0,13 \\
\hline
\end{tabular}

TABELA A-2- CLASSES DE RENDA FAMILIAR, ALUGUEL MÉDIO, RENDA MÉDIA E PARTICIPAÇÃO DO ALUGUEL NA RENDA FAMILIAR, SEGUNDO DECIS DE RENDA - BRASIL: 2004

\begin{tabular}{cccccc}
\hline $\begin{array}{c}\text { Decil } \\
\text { Renda }\end{array}$ & $\begin{array}{c}\text { Renda } \\
\text { Domiciliar }\end{array}$ & $\begin{array}{c}\text { A } \\
\text { Aluguel Médio } \\
\text { (em R\$) }\end{array}$ & $\begin{array}{c}\text { Y } \\
\text { Renda Média }\end{array}$ & Y/A & A/Y \\
\hline 1 & Até R\$297,00 & 106 & 196 & 1,86 & 0,54 \\
2 & $297 \mid-425$ & 123 & 360 & 2,93 & 0,34 \\
3 & $425 \mid-550$ & 148 & 496 & 3,34 & 0,30 \\
4 & $550 \mid-700$ & 166 & 632 & 3,80 & 0,26 \\
5 & $700 \mid-860$ & 185 & 790 & 4,28 & 0,23 \\
6 & $860 \mid-1.080$ & 213 & 972 & 4,56 & 0,22 \\
7 & $1.080 \mid-1.400$ & 242 & 1.233 & 5,11 & 0,20 \\
8 & $1400 \mid-1900$ & 286 & 1.632 & 5,71 & 0,18 \\
9 & $1900 \mid-3000$ & 354 & 2.386 & 6,73 & 0,15 \\
10 & Mais 3000 & 551 & 5.738 & 10,42 & 0,10 \\
\hline
\end{tabular}


TAFNER, P.; CARVALHO, M. Evolução da distribuição familiar...

TABELA A-3 - ESTATÍSTICAS GERAIS - ALUGUÉIS RECEBIDOS E PAGOS, VALOR DO ESTOQUE DE RESIDÊNCIA POR TIPO, ÍNDICE DE GINI DO ESTOQUE DE RESIDÊNCIA E DA RENDA

\begin{tabular}{lrrr}
\hline Variáveis & \multicolumn{1}{c}{1995} & \multicolumn{1}{c}{1999} & \multicolumn{1}{c}{2004} \\
\hline Aluguel médio (Preço Dez de 2000) & 276,66 & 386,79 & 238,41 \\
Total de aluguel recebido (R\$) & 1.059 .038 .500 & 977.441 .812 & 1.176 .287 .005 \\
Total de aluguel pago (R\$) & 1.550 .176 .020 & 1.353 .876 .189 & 1.863 .532 .694 \\
Valor do Estoque de Residência (em R\$ bi) & $1.210,47$ & $1.166,87$ & $1.543,68$ \\
Riqueza imobiliária & $1.103,03$ & $1.072,73$ & $1.444,45$ \\
$\quad$ Valor do Est. Residência-Próprio (idem) & 896,34 & 892,21 & $1.195,98$ \\
$\quad$ Valor do Est. Residência-Alugado (idem) & 206,69 & 180,52 & 248,47 \\
Valor Médio do Estoque de Residência & $31.461,68$ & $27.230,56$ & 35.249 \\
\hline Gini do valor do estoque de Residência & 0,699988618 & 0,661148091 & 0,611257 \\
$5 \%$ mais pobres & 0,025187 & 0,02931 & 0,00846 \\
$10 \%$ mais pobres & 0,031624 & 0,03786 & 0,02193 \\
$40 \%$ mais pobres & 0,152892 & 0,17356 & 0,15710 \\
$5 \%$ mais ricos & 0,244945 & 0,23813 & 0,30824 \\
$1 \%$ mais ricos & 0,088105 & 0,08726 & 0,09405 \\
\hline Gini da Renda & 0,578272365 & 0,57169768 & 0,514959508 \\
\hline $5 \%$ mais pobres & 0,001699 & 0,00172 & 0,003411 \\
$10 \%$ mais pobres & 0,007823 & 0,00833 & 0,012208 \\
$40 \%$ mais pobres & 0,085448 & 0,08863 & 0,106321 \\
$5 \%$ mais ricos & 0,310122 & 0,30728 & 0,285600 \\
\hline & 0,115502 & 0,11202 & 0,105273 \\
\hline
\end{tabular}

FONTE: Os dados para 1995 e 1999, estão em Reis et al. (2001). Para 2004, calculado pelos autores

Recebido em: 9 ago. 2006

Aceite em: 14 set. 2006 